\title{
Mechanical Properties and Failure Modes of CRCB Specimen Under Impact Loading
}

Wenjie Liu ( $\nabla$ wenjie_liu_auster@163.com )

Anhui University of Science and Technology

Ke Yang

Hefei Comprehensive National Science Center

Litong Dou

Anhui University of Science and Technology

Zhen Wei

Anhui University of Science and Technology

Xiaolou Chi

Anhui University of Science and Technology

Rijie Xu

Anhui University of Science and Technology

\section{Research Article}

Keywords: Coal-rock combined body, SHPB, Stress wave propagation, Dynamic stress-strain relationship, Energy evolution law, Crack propagation

Posted Date: January 4th, 2022

DOI: https://doi.org/10.21203/rs.3.rs-1204910/v1

License: (c) (i) This work is licensed under a Creative Commons Attribution 4.0 International License.

Read Full License 


\title{
Mechanical properties and failure modes of CRCB specimen under impact loading
}

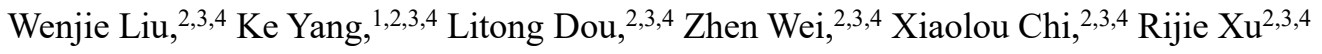 \\ (1.Institute of Energy, Hefei Comprehensive National Science Center, Anhui, Hefei, 230031, China; 2.State Key Laboratory of \\ Mining Response and Disaster Prevention and Control in Deep Coal Mines, Anhui University of Science and Technology, \\ Huainan 232001, China; 3. National \& Local Joint Engineering Research Center of precision coal mining, Anhui University of \\ Science and Technology, Anhui, Huainan, 232001, China; 4. Key Laboratory of Mining Coal Safety and Efficiently Constructed \\ by Anhui Province and Ministry of Education, Anhui University of Science and Technology, Huainan 232001, China)
}

To whom correspondence should be addressed: E-mail: wenjie_liu_auster@163.com

\begin{abstract}
To explore the dynamic mechanical characteristics of coal-rock combined body (CRCB) load-bearing structures, impact tests were performed on CRCB specimens by using a separated Hopkinson pressure bar test device (SHPB) combined with an ultra-high-speed camera system. The propagation characteristics of stress wave, dynamic stress-strain relationship, energy evolution law, and distribution characteristics of CRCB crushed particles in the impact tests were analyzed. The obtained results showed that: with the increasing of impact velocity, the effect of the wave impedance difference between the CRCB specimens and incident bar on stress wave propagation is gradually weakened. The peak strength $\left(\sigma_{\mathrm{II}}\right)$ and peak strain of the CRCB had obvious strain-rate effects, the ratio of reflected energy decreases linearly. In addition, with increased impact velocity, the growth rate of the peak strength and ratio of absorbed energy gradually dropped, changing approximately as a power function. Macro-fractures of the CRCB mainly occurred at the coal or rock ends which is far away from the interface. When the stress at the crack tip is greater than the "weakened" coal or rock strength, the crack will continue to develop across the coal and rock interface. With the increasing of impact velocity and rock strength, the crushed coal particles gradually transform from massive to powdering, and the average size of crushed coal blocks decreases, which leads to a gradual increase in the fractal dimension of the CRCB specimens. Therefore, the monitoring and prevention of dynamic loads should be strengthened in the coal mines with thick and hard roofs.
\end{abstract}

Key words:Coal-rock combined body; SHPB; Stress wave propagation; Dynamic stress-strain relationship; Energy evolution law; Crack propagation.

Introduction. During mining of coal seams, the coal stratum interacts with the upper (roof) and bottom (floor) rock strata, while the remaining coal body (coal pillar) and the rock layer form a new load-bearing stru cture, which is referred to as a coal-rock combined body $(\mathrm{CRCB})^{1,2 .}$ Due to excavation disturbance and strong underground pressure, the $\mathrm{CRCB}$ structure will inevitably experience dynamic stress waves. Because of the co mplicated structure of $\mathrm{CRCB}$ specimens, their stress wave propagation and attenuation characteristics differ fro $\mathrm{m}$ coal and rock single bodies. On the other hand, the dynamic response characteristics of the combined struct 
ure play a vital role in the stability of the roadway-surrounding rock-bearing system ${ }^{3-7}$. Therefore, the study of the propagation of stress waves in the CRCB specimens and their dynamic mechanical response characteristic $\mathrm{s}$ is very topical, since it can provide a better understanding of the stability of the CRCB structure, which has great significance to control the deformation and instability of surrounding rock in dynamic pressure roadways and ensure the safe and efficient mining of mines.

There are multiple in-depth studies on the mechanical properties ${ }^{8-13}$, energy evolution behaviour $^{14-16}$, deformation and failure characteristics ${ }^{17-22}$, constitutive models ${ }^{23,24}$ and destruction criteria ${ }^{25-27}$ of multiphase coal and rock layered composite structures via laboratory tests, theoretical analysis, numerical simulation, etc. For example, Chen et al. ${ }^{2}$ analysed the evolution of deformation and strength parameters of roof-coal pillar structures with different height ratios based on uniaxial compression tests of roof sandstone-coal pillar structures, which revealed the progressive failure mechanism of the coal-rock structure. Li et al. ${ }^{21}$ carried out impact tests on the CRCB specimens, determined their energy dissipation and crushing characteristics, and determined the influence law of the precast crack angle on their energy evolution and fractal characteristics. Gong et al. ${ }^{20}$ used SHPB test system to determine the impact mechanical characteristics of the CRCB under different strain rates. The test results showed that the dynamic compressive strength, dynamic peak strain, incident energy, and reflected energy of the CRCB had obvious strain rate effects. Under the action of impact stress waves, sandstone was mostly damaged by tensile rib spalling. Han et al. ${ }^{22}$ studied the dynamic characteristics of sandstone under different cement mortar cementation thicknesses and pointed out that with the increase of cementation thickness, the failure pattern of sandstone changed from tensile spalling to splitting. In terms of mechanical constitutive equations. Liu et al. ${ }^{23}$ established two kinds of damage constitutive models of coal bodies by connecting damaged bodies and Newtonian body, which revealed the influence of rock on the mechanical behaviour of coal in the CRCB specimens.Based on the impact loading tests of $\mathrm{CRCB}$ specimens with different combination ratios. Xie and Zheng ${ }^{24}$ constructed a multi-parameter composite constitutive model of CRCB specimens, and the model fitting curve was in good agreement with the measured dynamic constitutive curve. Zhao et al. ${ }^{25}$ established an equivalent uniform model of CRCB based on the principle of equivalent strain energy in terms of failure criteria. They derived the compression-shear failure criterion considering the cohesive strength of the coal-rock interface. Yin et al. ${ }^{26}$ used the homogenization theory to treat the composite rock formations as an equivalent homogeneous rocks and then established a failure criterion for the layered composite rock based on the modified Lade criterion under true triaxial stress conditions.

The above findings provide some insight into the effects of the coal-rock height ratio, multiphase rock cementation characteristics, and stress loading methods on the mechanical properties, deformation, and failure characteristics of layered $\mathrm{CRCB}$ structures. However, most research efforts have been focused on static loading-related cases, while several researchers proved that the dynamic characteristics of composite rock masses significantly differed from static ones due to the wave impedance effect ${ }^{28}$. Therefore, this study adopted the SHPB test system and took the CRCB formed by the layered combination of four typical rock samples and the same coal 
sample as the research objects to analyse the impact of different lithology combinations on the dynamic stress-strain relationship, dynamic fracture evolution, and fracture characteristics of the CRCB. This study is expected to provide a reference for the excavation and protection of geological bodies of coal and rock composites.

\section{SHPB test of CRCB specimens}

Preparation of CRCB specimens from rock and coal samples. The coal samples required for the preparation of the CRCB specimen tests were acquired from the 401111 working face of the Hujiahe Coal Mine, which is one of thirteen coal mines located in the Binchang Mining Area, Shanxi Province of China (Fig.1). The \#4 coal seam has a high burst tendency ${ }^{29}$. The rock samples were collected from some rock burst mines in Huainan, Shandong, and Inner Mongolia, China. The coal and rock samples with good integrity and homogeneity were cored and cut, and processed into $\Phi 50 \mathrm{~mm} \times 25 \mathrm{~mm}$ cylinder samples. The rock grinding machine was used to polish the two end faces of the coal and rock samples, and the non-parallelism and non-perpendicularity of the end faces of the coal and rock samples were controlled within $\pm 0.02 \mathrm{~mm}$. Epoxy resin is used to splice processed coal and rock samples to obtain CRCB samples. The amount of epoxy resin and bonding thickness are strictly controlled in the splicing process. According to the sample combinations, four sets of CRCB specimens were produced (Fig.2), which comprised: (i) yellow mudstone-coal sample (MC), (ii) sandy mudstone-coal sample (SM-C), (iii) white sandstone-coal sample (WS-C), and (iv) black sandstone-coal sample (BS-C). When each specimen was processed, it was required that the size and processing accuracy of the coal and rock single body samples and the CRCB specimens met the standard ISRM requirements. In addition, the uniaxial compression specimens and Brazilian discs were prepared from rock and coal samples. The basic mechanical parameters of the coal and rock samples were determined and listed in Table 1.

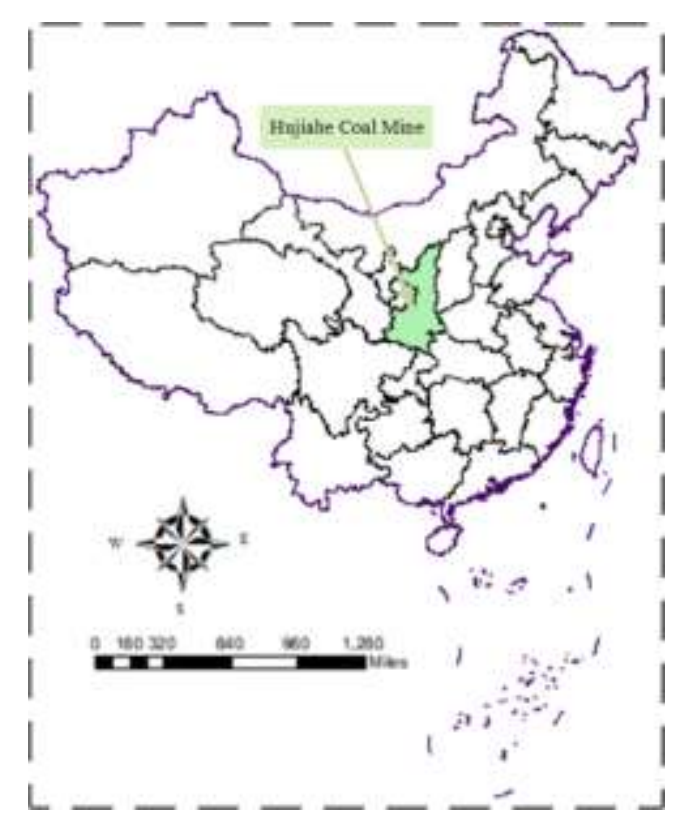

Fig. 1. The location of Hujiahe Coal Mine 


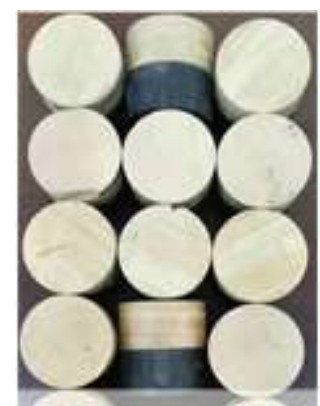

Yellow mudstonecoal combined body

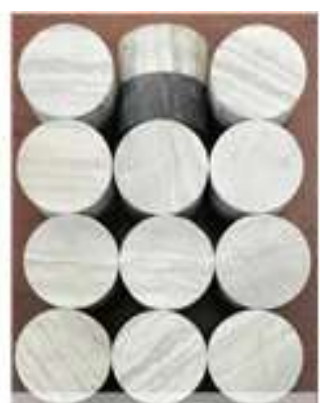

SandyMudstone-coal combined body
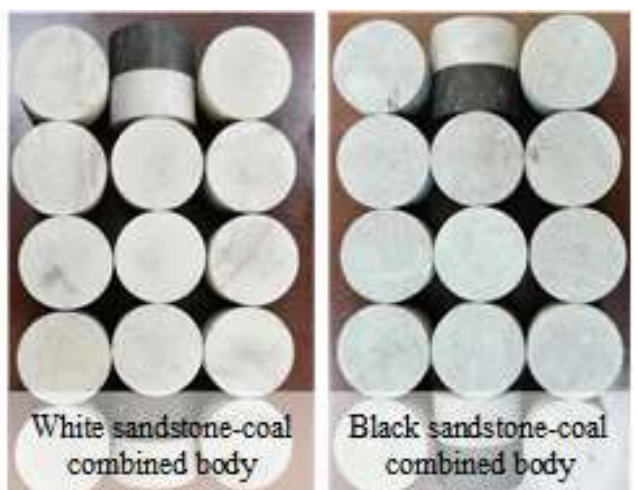

Fig. 2. CRCB specimens prepared with four different rock sample and identical coal samples

Table 1. Mechanical parameters of coal and rock samples

\begin{tabular}{|c|c|c|c|c|c|c|}
\hline Lithology & $\begin{array}{l}\text { Compressive } \\
\text { strength/MPa }\end{array}$ & $\begin{array}{c}\text { Elastic } \\
\text { modulus/GPa }\end{array}$ & $\begin{array}{c}\text { Tensile } \\
\text { strength/MPa }\end{array}$ & $\begin{array}{l}\text { Poisson's } \\
\text { ratio }\end{array}$ & $\begin{array}{l}\text { Longitudinal wave } \\
\text { velocity } /\left(\mathrm{m} \cdot \mathrm{s}^{-1}\right)\end{array}$ & Density $/\left(\mathrm{kg} \cdot \mathrm{m}^{-3}\right)$ \\
\hline Yellow mudstone & 8.43 & 1.07 & 0.81 & 0.22 & 2976 & 2124 \\
\hline Sandy mudstone & 13.36 & 1.92 & 1.28 & 0.19 & 3276 & 2279 \\
\hline White sandstone & 44.62 & 6.65 & 4.06 & 0.16 & 3846 & 2577 \\
\hline Black sandstone & 65.29 & 7.12 & 5.02 & 0.14 & 3452 & 2718 \\
\hline Coal sample & 13.87 & 2.04 & 1.32 & 0.25 & 2420 & 1481 \\
\hline
\end{tabular}

\section{SHPB test system and test plan}

Test system. Impact compression tests of the CRCB specimens were conducted by using the SHPB test system and ultra-high-speed camera system in the State Key Laboratory of Mining Response and Disaster Prevention and Control in Deep Coal Mines, Anhui University of Science and Technology, China. As shown in Fig.3, the incident bar, transmission bar and bullet of SHPB test device are cylindrical steel bars with diameters of $50 \mathrm{~mm}$, elastic modulus of $210 \mathrm{GPa}$ and longitudinal wave velocity of $5190 \mathrm{~m} / \mathrm{s}$. During the test, impact velocity and amplitude of the incident stress waves were controlled by adjusting the nitrogen pressure inside the high-pressure chamber or changing the position of the spindle punch. Dynamic strain gauges (SG1 and SG2) and SDY2107A super-dynamic strain gauge were used to measure strain signals in the incident and transmission bars. And then strain signals were stored and displayed by Yokowaga-DL850E oscilloscope. Ultra-high-speed camera system was composed of a FASTCAM SA-Z high-speed camera and flash. Before the test, the image resolution, shooting speed, and shooting time of the high-speed camera were preset at 256 pixel $\times 408$ pixel, $120000 \mathrm{fps}$, and $200 \mu \mathrm{s}$, respectively. When the bullet hits the incident bar, the incident pulse signal will be generated, which is converted into voltage signal by the dynamic strain gauges (SG1) at the front of the incident bar. The voltage signal will make the SDY2107A super-dynamic strain gauge to trigger the operation of high-speed camera and flash. The system can clearly capture the whole process of sample failure and meet the test requirements. 


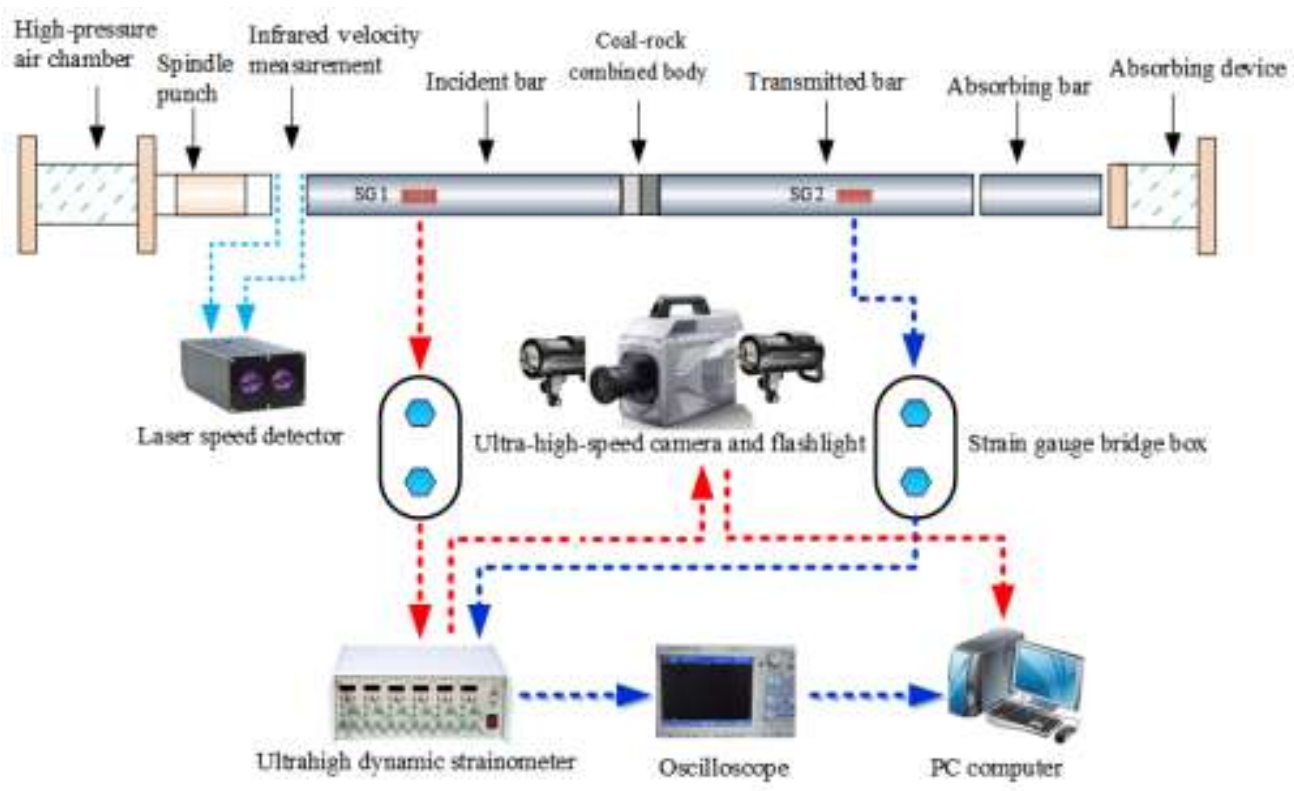

Fig. 3. The SHPB test system

Test plan. The impact test design of CRCB specimens envisaged that during the impact loading process, the stress wave entered the coal component from the rock component. Table 1 shows that the physical and mechanical parameters of the selected coal and rock samples were quite different. The uniaxial compressive strength values and elastic moduli of the rocks ranged from $8 \sim 70 \mathrm{MPa}$ and 1 8 GPa, respectively. Therefore, it was crucial to select an appropriate impact air pressure and impact velocity. Therefore, impact trials were performed on the coal and rock samples before the test. The trial results show that the mudstone and coal samples with lower strength were more intensively fractured under the action of low impact pressure. When the impact pressure exceeded 0.6 $\mathrm{MPa}$, macroscopic crack initiation and expansion began to occur in the sandstone. Therefore, the impact tests were performed under five impact air pressures of $0.4,0.5,0.6,0.7$, and $0.8 \mathrm{MPa}$, with more than three specimens tested at each impact air pressure. Before the tests, a thin layer of Vaseline was applied to the contact between the specimen and the bar to reduce the friction effect on the end surface.

Dynamic stress balance verification. To ensure the reliability of the test results, the stress balance of CRCB specimen was verified. Fig.4 shows the stress evolution in a CRCB specimen subjected to impact compression loading, where the sum of the incident stress and the reflected stress is approximately equal to the transmission stress, indicating that the stress balance conditions is satisfied.Other group tests also satisfy stress balance conditions, which will not be described here. 


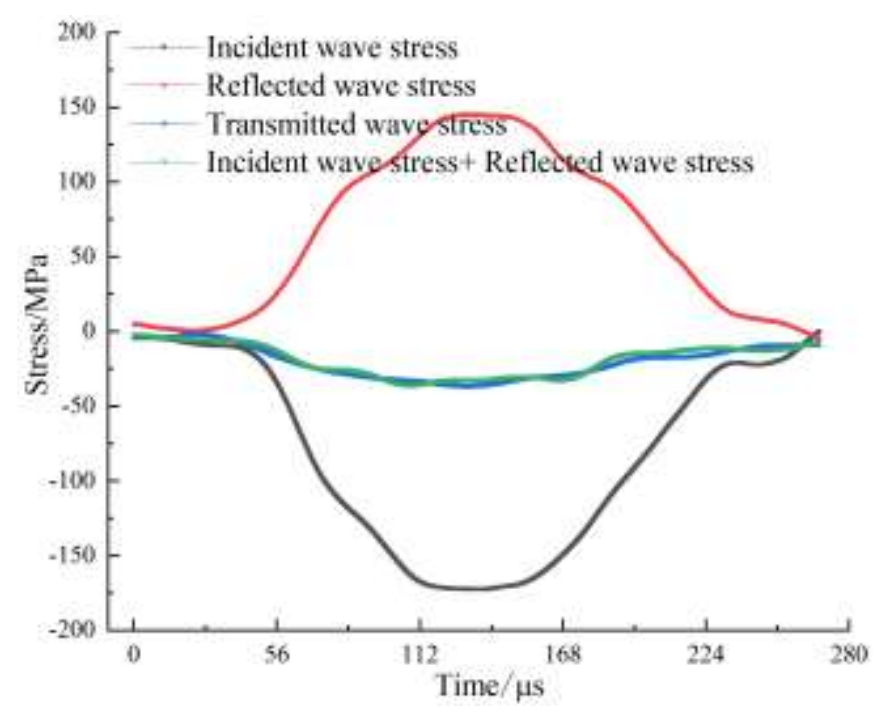

Fig. 4. Verification of dynamic stress balance for a typical specimen

\section{Test Results and Analysis}

Stress wave propagation characteristics. Comparing the stress wave characteristics of CRCB specimen under different impact velocities (Fig.5), it can be obtained that as the impact velocity is increased, the amplitudes of the incident wave, reflected wave, and the transmitted wave of the CRCB specimen gradually increase. Under the same impact velocity, the incident waves of each group of CRCB specimen were the same. However, as the wave impedance of rock increased, the amplitude of the transmitted wave gradually increased, while the reflected wave amplitude decreased. Such a difference was more obvious when the impact velocities is range from $7 \mathrm{~m} / \mathrm{s}$ to $10 \mathrm{~m} / \mathrm{s}$, but less pronounced at high impact velocities $(10 \sim 12 \mathrm{~m} / \mathrm{s})$. From the stress wave propagation characteristics, it can be concluded that the greater of the rock wave impedance is, the better matching effect between the combined body and the incident bar are. More stress waves will propagate to the transmission bar through the CRCB specimen when the incident wave propagates to the interface between CRCB specimen and the incident bar. Therefore, under the same impact velocity, the amplitude of the transmission wave of WS-C should be the largest, while the amplitude of the transmission wave of M-C should be the smallest. However, as the impact velocity increases, the matching effect of the $\mathrm{CRCB}$ specimen wave impedance and the incident bar wave impedance influence on the stress wave propagation becomes gradually decreases, resulting in similar amplitudes of transmitted waves.

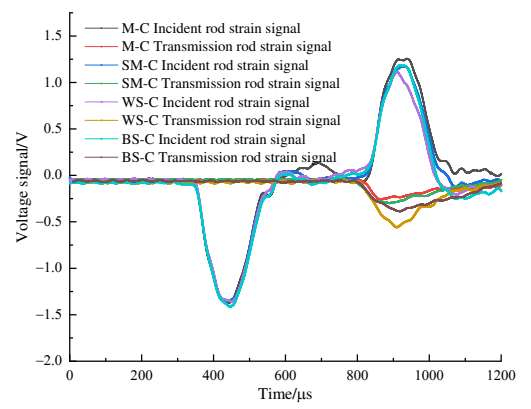

(a) $7.2 \mathrm{~m} / \mathrm{s}$

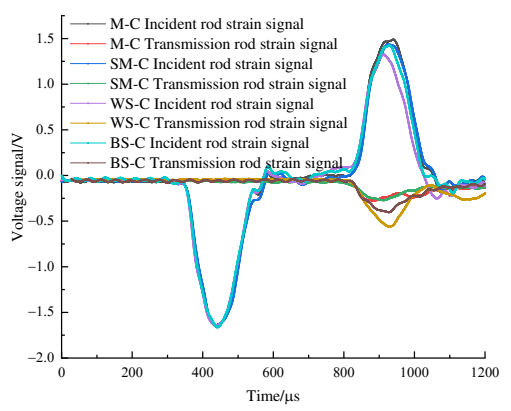

(b) $8.5 \mathrm{~m} / \mathrm{s}$

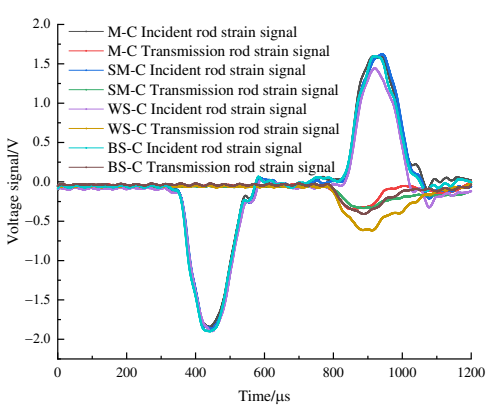

(c) $9.7 \mathrm{~m} / \mathrm{s}$ 


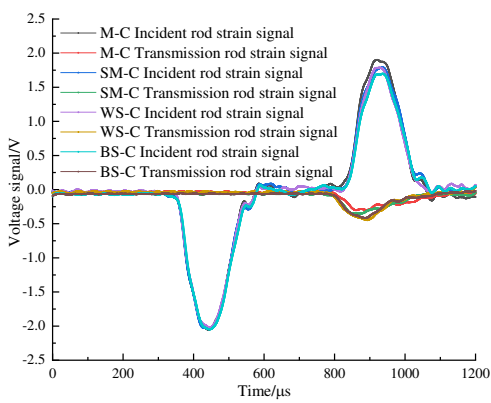

(e) $10.7 \mathrm{~m} / \mathrm{s}$

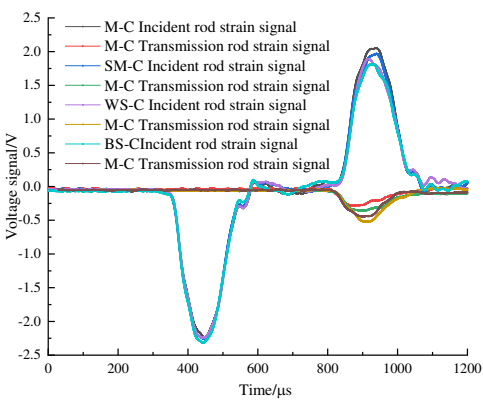

(f) $11.8 \mathrm{~m} / \mathrm{s}$

Fig. 5. The waveforms in $\mathrm{CRCB}$ specimens at different impact velocities

Characteristics of the dynamic stress-strain curve. Based on the assumption of one-dimensional stress wave and stress-strain uniformity, according to the incident wave $\varepsilon_{\mathrm{I}}(t)$ and reflected wave $\varepsilon_{\mathrm{R}}(t)$ measured by the strain gauge on the incident bar and the transmitted wave $\varepsilon_{\mathrm{T}}(t)$ measured by the strain gauge on the transmission bar. The stress and strain on both ends of the specimen can be calculated:

$$
\begin{gathered}
\sigma(t)=\frac{A_{0}}{2 A_{S}} E_{0}\left[\varepsilon_{I}(t)+\varepsilon_{R}(t)+\varepsilon_{T}(t)\right] \\
\varepsilon(t)=\frac{C_{0}}{L_{S}} \int\left[\varepsilon_{I}(t)-\varepsilon_{R}(t)-\varepsilon_{T}(t)\right] d t
\end{gathered}
$$

Where $\mathrm{A}_{0}$ is the cross-sectional area of the bar, $\mathrm{mm}^{2} ; \mathrm{E}_{0}$ is the elastic modulus of the pressure bar, $\mathrm{GPa} ; \mathrm{C}_{0}$ is the longitudinal wave velocity of the member, $\mathrm{m} / \mathrm{s}$; $\mathrm{L}_{\mathrm{s}}$ is the length of sample, $\mathrm{mm}$; As is the cross-sectional area of the sample, $\mathrm{mm}^{2}$.

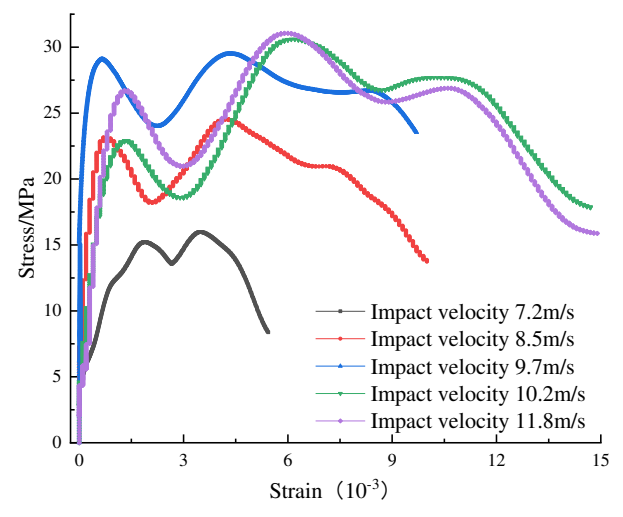

(a) $\mathrm{M}-\mathrm{C}$

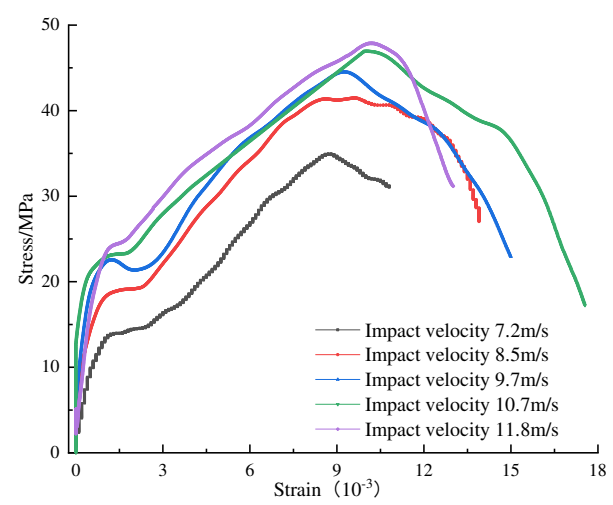

(c) WS-C

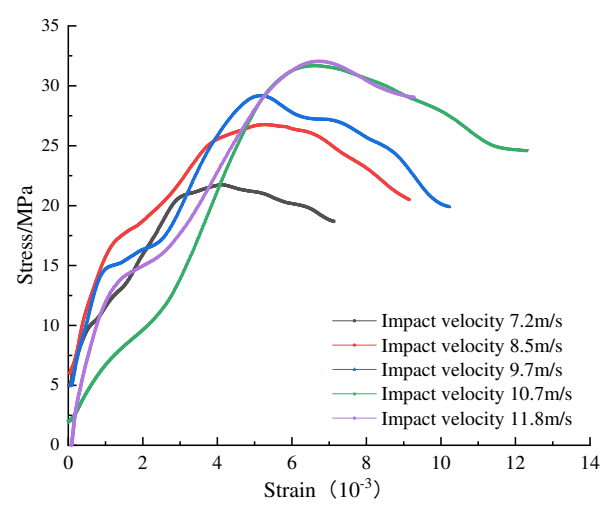

(b) SM-C

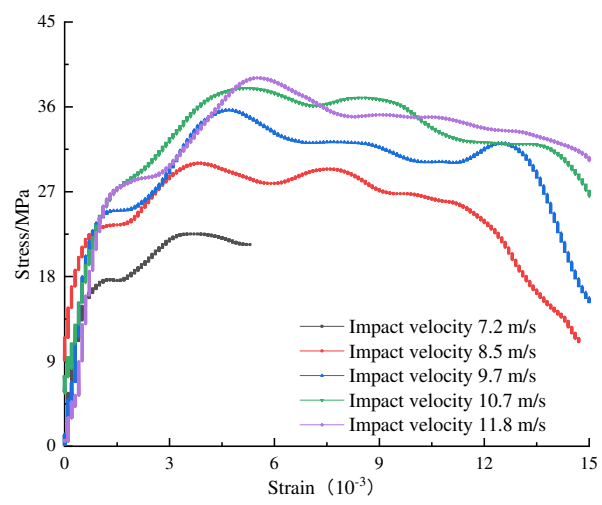

(d) BS-C 
Fig. 6. Equivalent stress-strain curves of CRCB specimens.

Fig.6 shows that the stress-strain curves within the same CRCB group were similar, while the shapes of the stress-strain curves in different CRCB specimen groups were quite different. The propagation and attenuation patterns of stress waves in the same type of CRCB specimen were similar. The CRCB specimen had no pronounced compression and compaction stages. In addition, when the coal and rock in the CRCB specimen had large differences in mechanical properties, the stress-strain curve mostly presented a "bimodal" distribution before the dynamic stress-strain curve reached peak strength $\left(\sigma_{\mathrm{II}}\right)$.
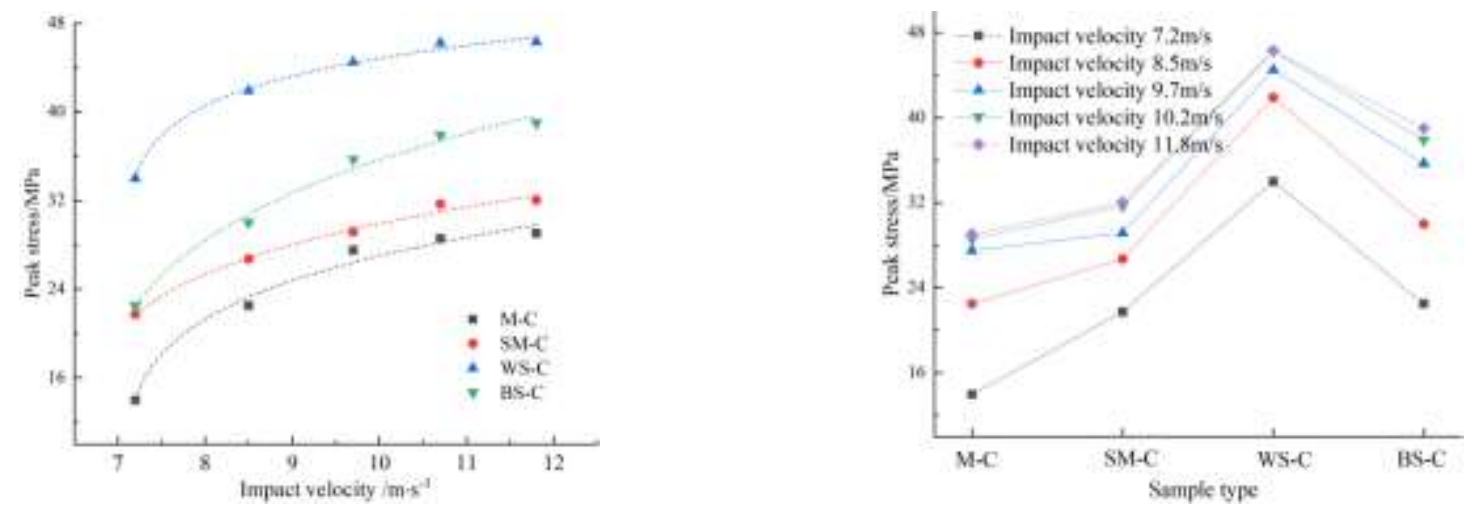

(a) Relationship between dynamic peak stress (II) and impact velocity
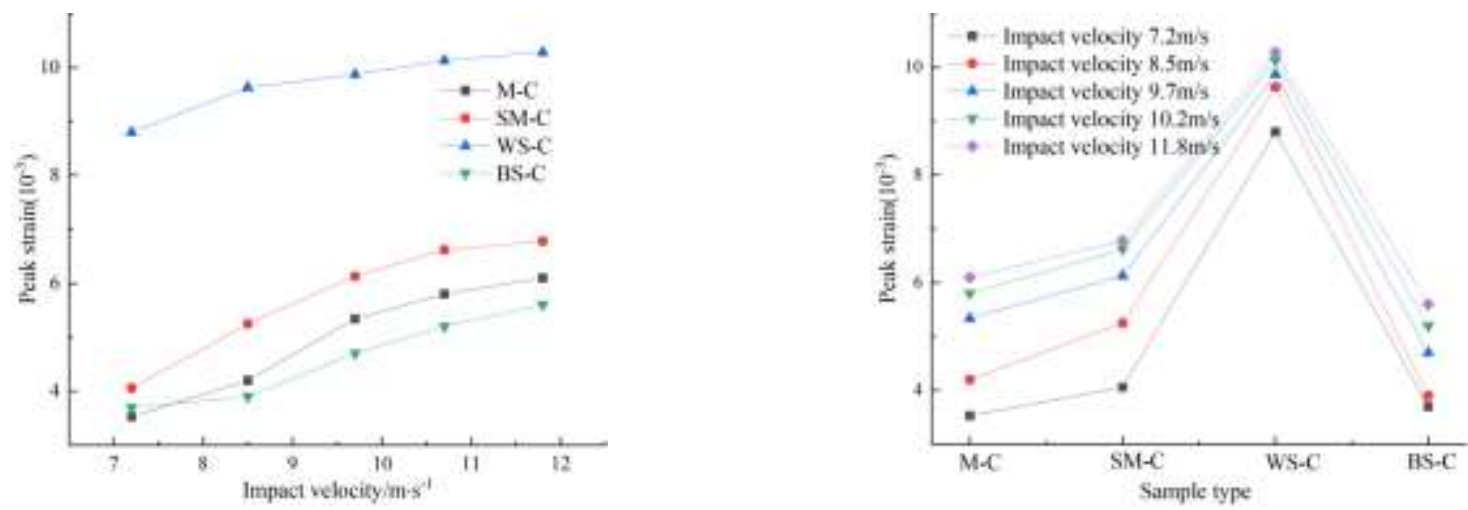

(b) The relationship between peak strain and impact velocity

Fig. 7. Peak stresses and peak strain s of CRCB specimens

The stress-strain curve of the CRCB specimen possessed obvious nonlinear characteristics before it reached the first dynamic peak stress $\left(\sigma_{\mathrm{I}}\right)$. With an increase in impact velocity, $\sigma_{\mathrm{I}}$ showed no obvious regular changes: at low impact velocity $\sigma_{I}$ was significantly smaller than at high impact velocity. As the impact velocity increased, the peak strength $\left(\sigma_{\mathrm{II}}\right)$ exhibited a significant strain rate effect. Fig.7(a) shows that $\sigma_{\text {II }}$ increased rapidly under low impact velocity and then slowly with the impact velocity increase. $\sigma_{\text {II }}$ was approximately a power function of the impact velocity. The equation $\mathrm{y}=a(x-b)^{\mathrm{c}}$ was used for its best fitting, and the fitting parameters $a, b$, and $c$ are listed in Table 2.

Table 2. Fitting parameters

\begin{tabular}{ccccc}
\hline Sample type & $\mathrm{a}$ & $\mathrm{b}$ & $\mathrm{c}$ & $\mathrm{R}^{2}$ \\
\hline M-C & 21.66 & 7.08 & 0.20 & 0.968 \\
SM-C & 23.57 & 6.54 & 0.19 & 0.981
\end{tabular}




\begin{tabular}{lllll} 
WS-C & 40.82 & 7.07 & 0.08 & 0.989 \\
BS-C & 26.71 & 6.71 & 0.24 & 0.978 \\
\hline
\end{tabular}

As shown in Fig.7(b), with an increase in the strength and elastic modulus of rock at the same impact velocity, the peak strength and peak strain of CRCB specimen first increased and then decreased. Compared to those of WS-C, the peak strength and peak strain of BS-C were significantly smaller. The dynamic stress-strain curve of WS-C increased tortuously before reaching the peak strength $\left(\sigma_{\mathrm{II}}\right)$, showing obvious strain-hardening characteristics. Compared with that of WS-C, the stress-strain curves of MC, SM-C, and BS-C were approximately straight lines before reaching the peak strength $\left(\sigma_{\mathrm{II}}\right)$, the slopes of which did not change greatly with the impact velocity. After the stress of the combined body reached the peak strength $\left(\sigma_{\mathrm{II}}\right)$, the dynamic stress-strain curve underwent several "ups and downs". This indicates that the strain-hardening characteristic of the combined body was remarkable, and the plastic deformation was enhanced.

Analysis of energy dissipation characteristics. Energy accumulation, release and dissipation occur in the process of deformation and failure of $\mathrm{CRCB}$ specimen. It is of great significance to study the energy dissipation law of CRCB specimen under impact loading for improving the anti-impact characteristics of surrounding rock bearing structure of roadway under coal and rock composite engineering. Assumed that there is no heat exchange between the sample and the surrounding environment during the test, and acoustic emission energy and electromagnetic radiation energy are ignored. The energy carried by stress wave can be calculated:

$$
\begin{aligned}
& W_{I}=A_{0} E_{0} C_{0} \int \varepsilon_{I}^{2}(t) d t \\
& W_{R}=A_{0} E_{0} C_{0} \int \varepsilon_{R}^{2}(t) d t \\
& W_{T}=A_{0} E_{0} C_{0} \int \varepsilon_{T}^{2}(t) d t
\end{aligned}
$$

Where $\mathrm{W}_{I} 、 \mathrm{~W}_{R}$ and $\mathrm{W}_{T}$ represent the energy carried by the incident wave, reflected wave and transmitted wave respectively.

According to the principle of energy conservation, ignoring the energy loss caused by friction between the pressure bar and the sample in the process of stress wave propagation, the energy absorbed by the CRCB specimen $\left(\mathrm{W}_{\mathrm{A}}\right)$ under impact can be obtained:

$$
W_{A}=W_{I}-W_{R}-W_{T}
$$

In order to analyze the law of energy propagation and dissipation of CRCB specimen under dynamic loading, the ratio of absorbed energy to incident energy of specimen is defined as absorbed energy ratio $(\lambda)$, and the ratio of reflected energy to incident energy is defined as reflected energy ratio $(\beta)$.

$$
\lambda=\frac{W_{A}}{W_{I}}
$$




$$
\beta=\frac{W_{R}}{W_{I}}
$$

Where $\lambda$ is absorbed energy ratio, $\beta$ is reflected energy ratio.

The incident energy, reflected energy, transmitted energy and absorbed energy of CRCB specimen under different impact velocities can be calculated by Eq. 3-8. The relationship between the incident energy, the absorbed energy ratio, the reflected energy and impact velocity can be obtained by analysis, as shown in Fig.8-10. Fig.8-9 shows that with the increase of impact velocity, the incident energy has nothing to do with the sample itself and increases approximately linearly. The ratio of reflected energy decreases linearly with the increase of impact velocity in the same group of CRCB specimen. Combined with the analysis of stress wave propagation characteristics, it is easy to understand that under the action of the same impact velocity, the better the impedance matching effect of rock and incident bar wave is, the more energy will be transmitted to the CRCB specimen with incident wave, and the proportion of reflected energy will decrease. Therefore, compared with other groups, the $\beta$ of WS-C specimen is relatively minimum. On the other hand, with the increase of impact velocity, the effect of impedance matching between rock and incident bar wave is gradually weakened, and more incident energy will be transmitted to CRCB specimen, and the ratio of reflected energy will gradually decrease.

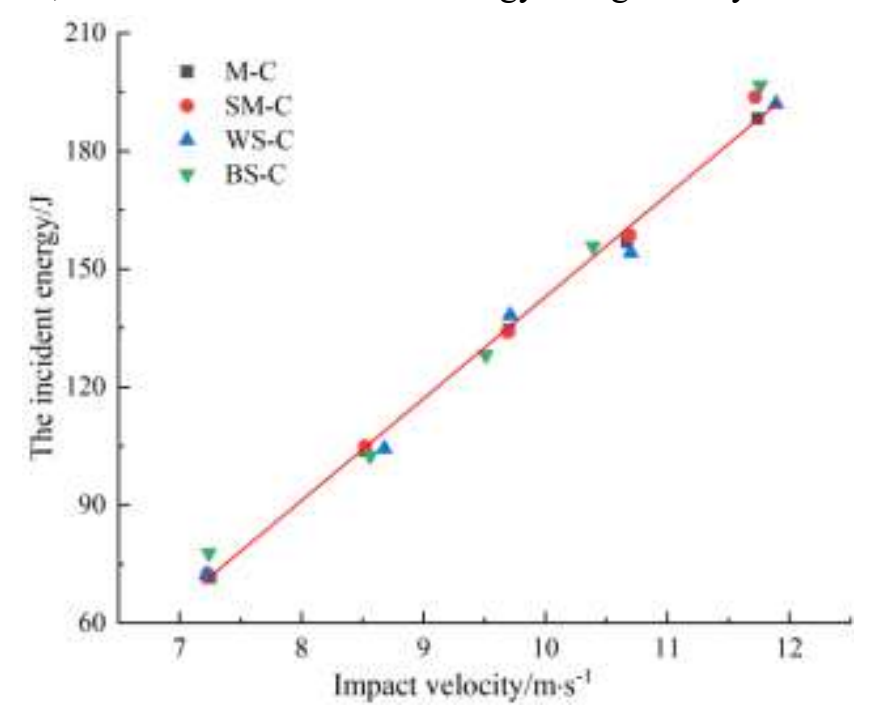

Fig. 8 The relationship between impact velocity and incident energy 


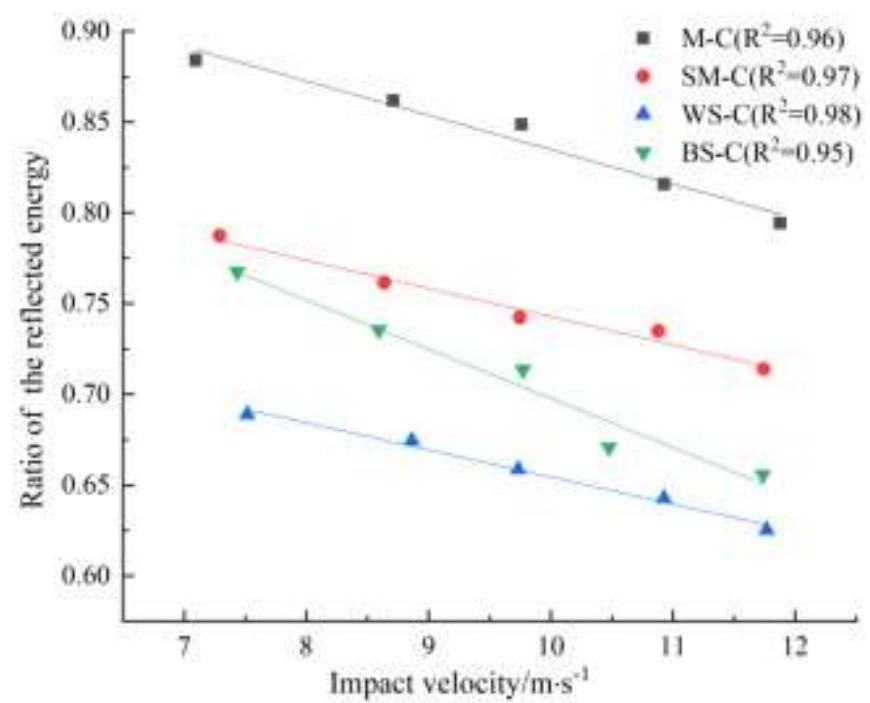

Fig. 9 The relationship between impact velocity and ratio of the reflected energy

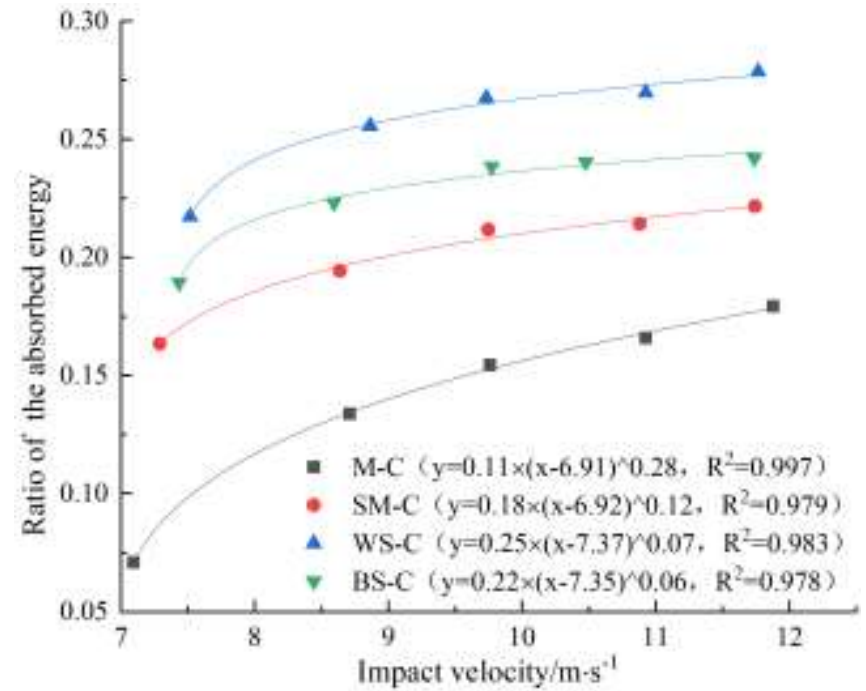

Fig. 10 The relationship between impact velocity and ratio of the absorbed energy

As can be seen from Fig.10, the ratio of absorbed energy increases with the increase of impact velocity, but the growth rate tends to decrease, approximately presenting a power function growth. The analysis shows that under the same impact velocity, when the rock strength is low, the energy storage limit of CRCB specimen is relatively low, and less energy is required for deformation and failure.

With the increase of impact velocity, the degree of breakage of CRCB specimen gradually increases, and the energy absorbed by the specimen also increases. However, when the impact velocity is greater than a certain value, on the premise of not changing boundary conditions, the fragmentation degree of the composite tends to be stable, and the energy absorbed during the failure of the composite increases slowly. The proportion of absorbed energy gradually flattens out. It is worth noting that although the strength of black sandstone is greater than that of white sandstone, the $\lambda$ of WS-C is greater than that of BS-C. This phenomenon will be further analyzed in combination with the fracture characteristics of the composite.

Dynamic evolution characteristics of cracks. The failure mode of the CRCB specimen reflects its ability to resist impact damage. Using a high-speed camera to capture the fracture process in the $\mathrm{CRCB}$, the dynamic evolution 
process of cracks in the CRCB was obtained, as shown in Table 3. According to the author's existing research [11], when the CRCB specimen deforms and fails, the coal or rock with large elastic modulus and small Poisson's ratios are weakened at the coal and rock interface. In contrast, the coal and rock with small elastic modulus and large Poisson's ratios are strengthened. In the whole dynamic loading process, the axial compressive stress, elastic modulus of rock and Poisson's ratio are time-varying quantities, and are affected by impact velocity and strain rate. The lateral constraint stress is a variable. However, in the process of dynamic loading, the relationship between the elastic modulus and poisson's ratio of coal and rock remains unchanged. In other words, the change of axial compressive stress, elastic modulus and Poisson's ratio of coal and rock only has effect on the degree of weakening or strengthening of coal and rock at the interface. The lateral constraint stress may be not as pronounced as the real stress effect. However, theoretically it exists and directly affects the initiation, expansion, and arrest of cracks at the CRCB specimen interface.

Table 3. Deformation and failure process of CRCB specimens

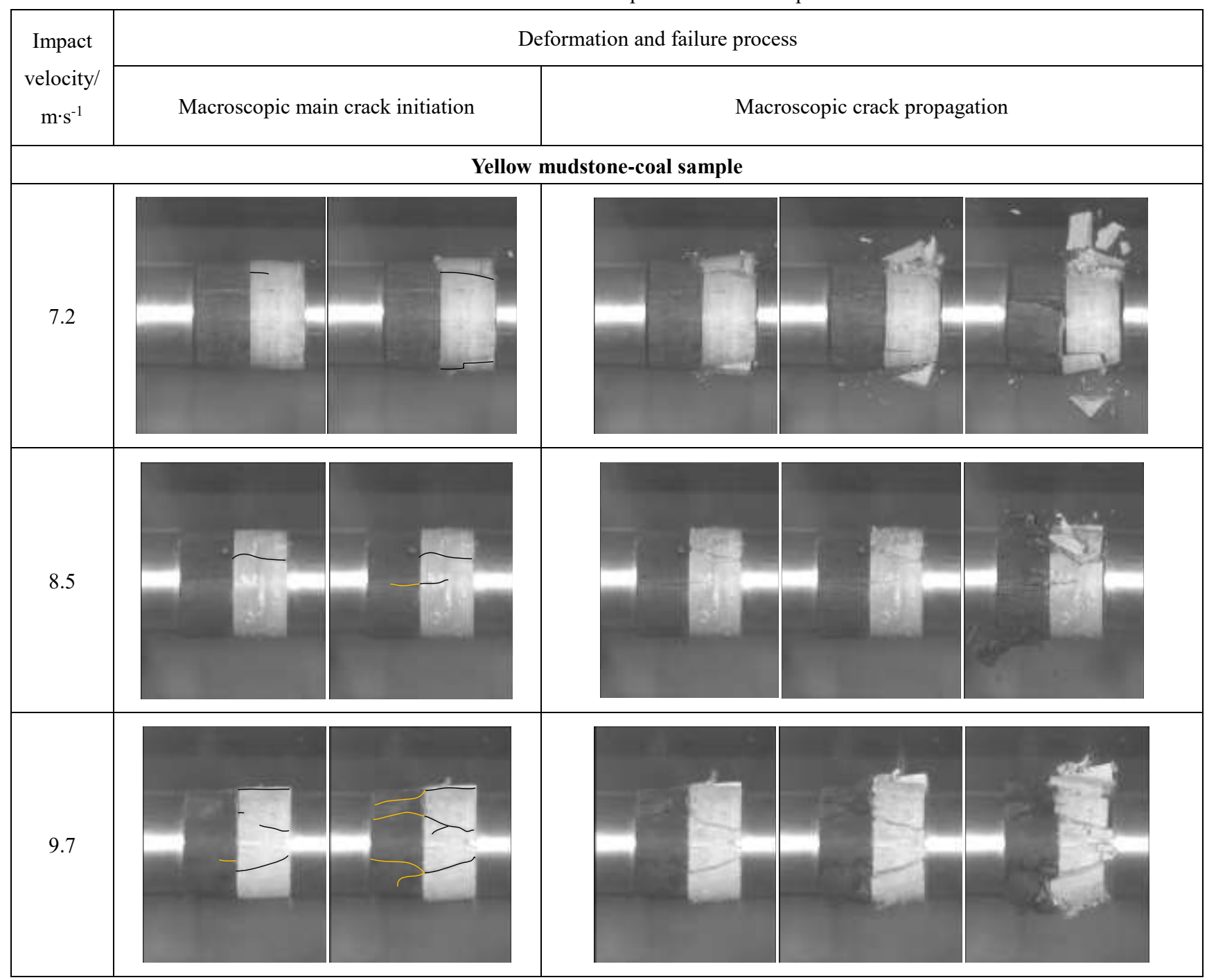




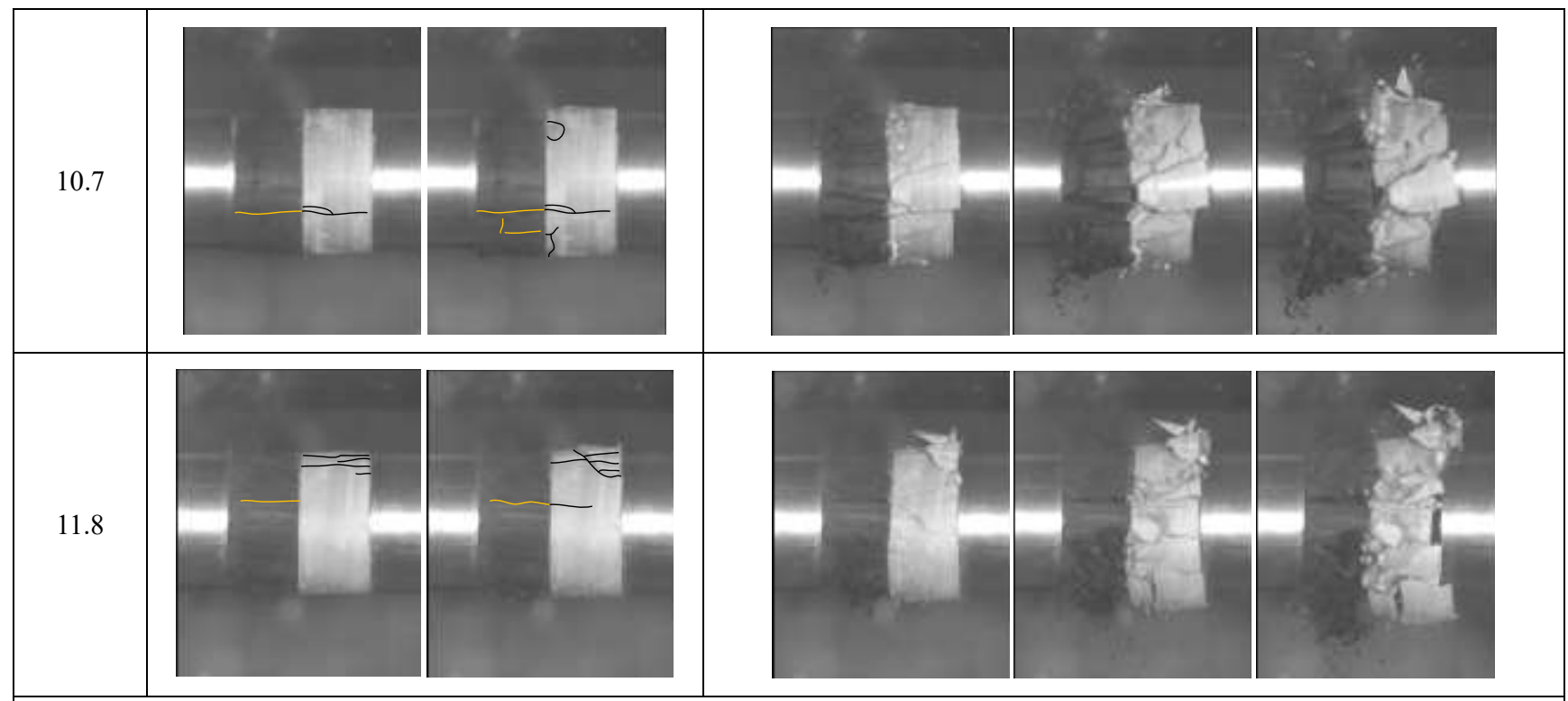

Fracture pattern:

(1) Under the action of impact load, most cracking and failure of the M-C sample occurred in the yellow mudstone far away from the coal-rock interface. Additionally, the number of cracks in the yellow mudstone is larger than in the coal body at the initial loading stage.

(2) Under the continuous action of the stress wave, combined with existing studies (Yang et al. 2020), when the stress at the crack tip exceeds the strength of the weakened coal body, part of the cracks in the yellow mudstone at the interface will develop across the coal-rock interface to the coal body, inducing the overall failure of the combined body.

(3) The coal samples show tensile splitting failure, while compression-shear fractures dominate the yellow mudstone.

(4) With an increase in the impact velocity, the cracks develop intricately in the combined body. The combined body is split by cracks, and the degree of fragmentation gradually increases. Fragmentation of the broken body gradually decreases, and the number of fragments increases. Compared with the coal samples, yellow mudstone is damaged more severely and has a higher degree of fragmentation.

(5) It can be seen from the initiation, propagation, and crack arrest behaviour of the surface cracks in CRCB that the strength of sandstone far away from the interface is less than the strength of sandstone at the interface, which is less than the strength of coal at the interface, which, in turn, is less than the strength of coal far away from the interface.

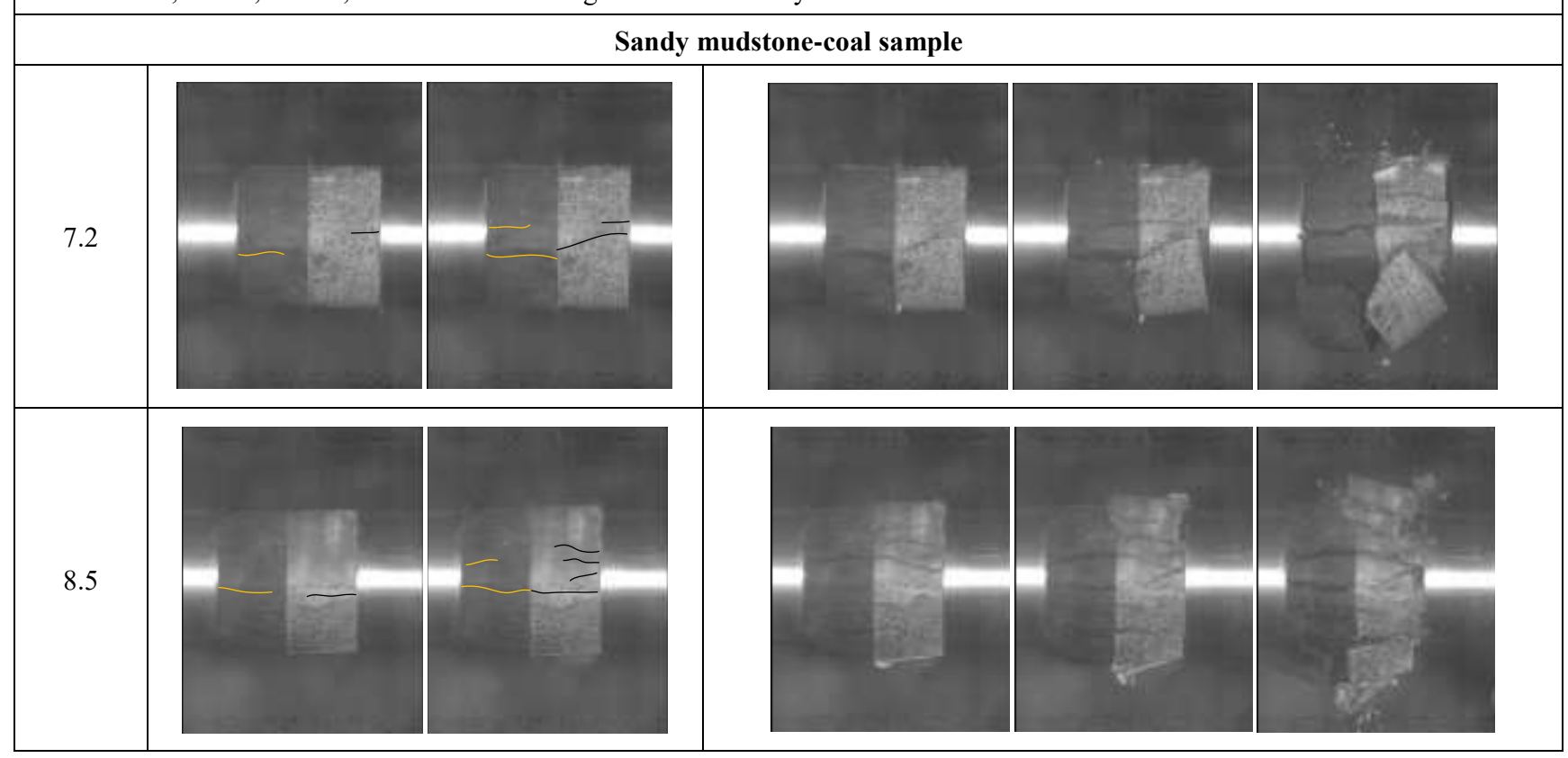




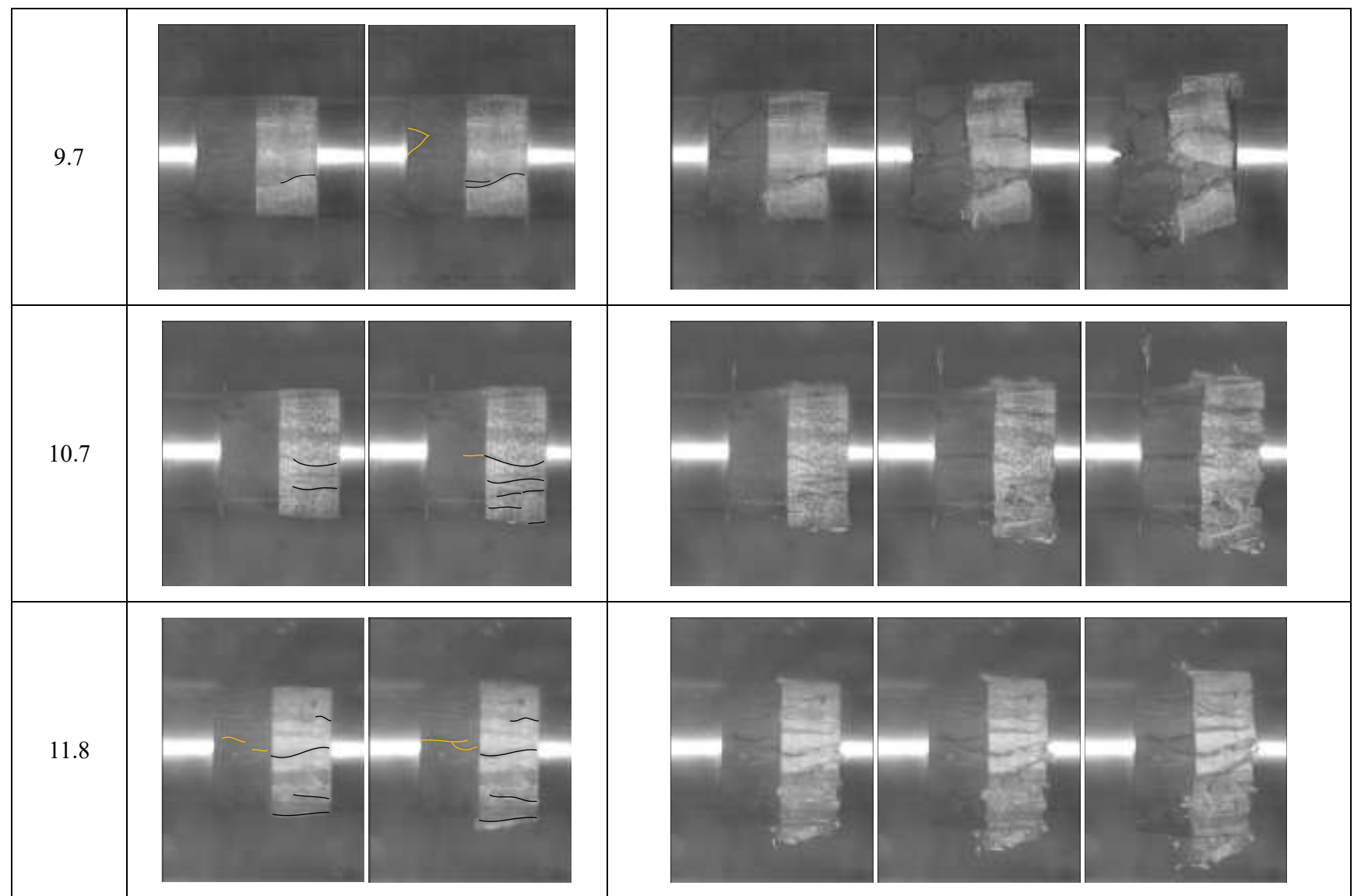

\section{Fracture pattern:}

(1) The initiation of macroscopic cracks in SM-C specimens is not concentrated in a certain component but appears randomly in the CRCB.

(2) Under the action of stress wave of dynamic load, the main cracks of SM-C specimens are mostly vertical (stress loading direction) cracks. When the main crack crosses the coal-rock interface, the direction of crack propagation generally does not change.

(3) As the impact velocity increases, the coal and rock components of the combined body become more broken. Both the coal and rock components mainly experience tensile fracture failure.

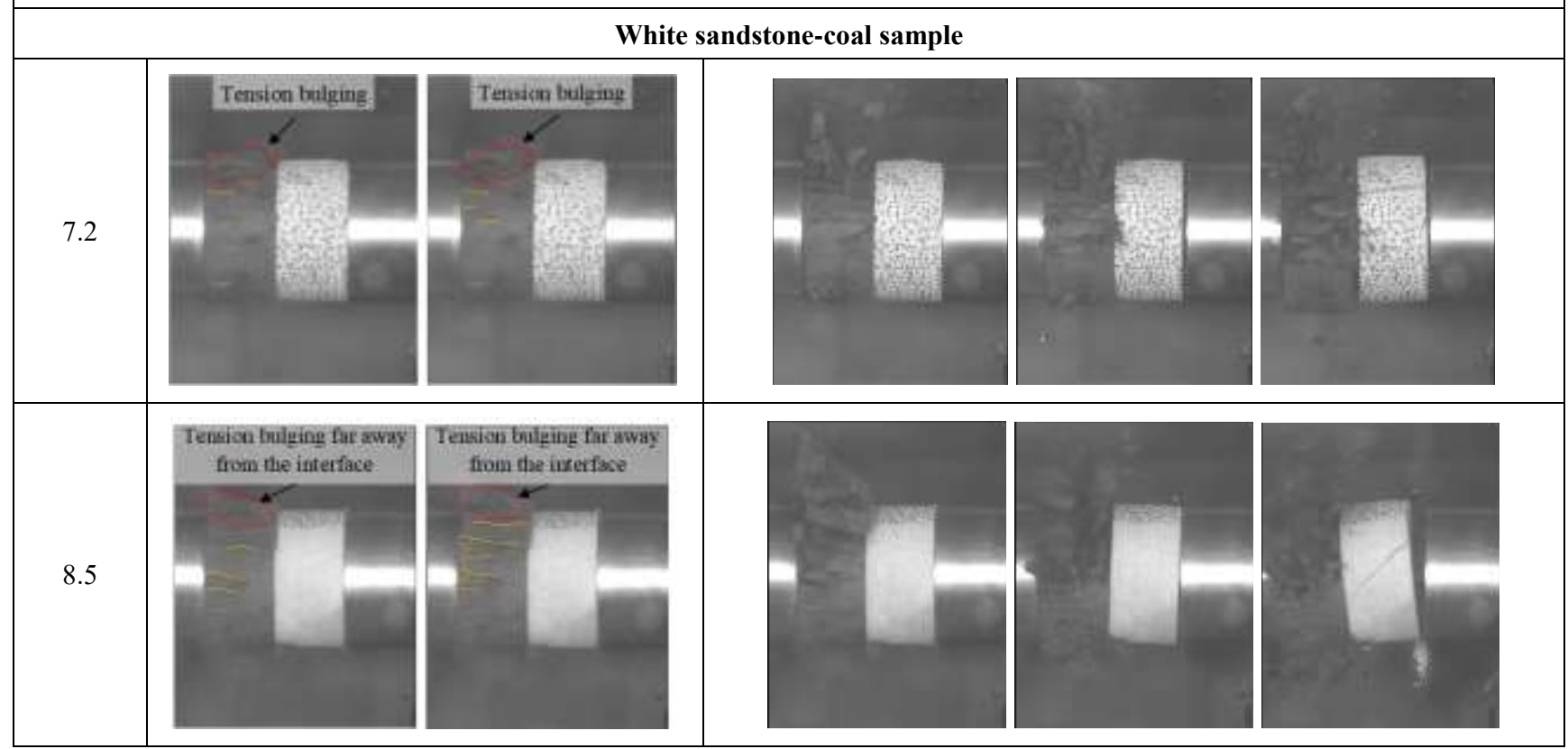




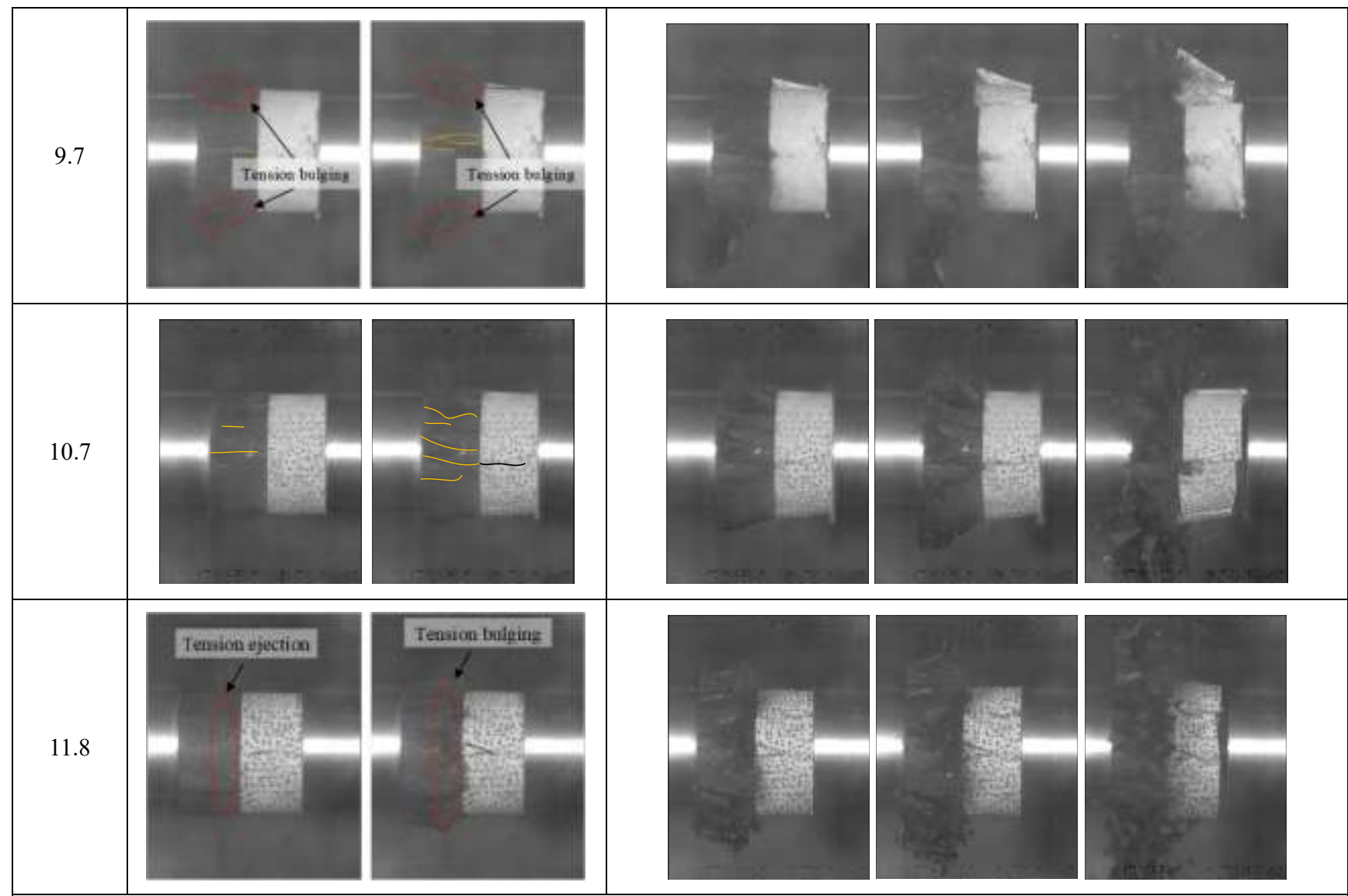

\section{Fracture pattern:}

(1) At the initial stage of impact loading, the macroscopic cracks in the WS-C specimen are mainly concentrated in the coal. The coal body far away from the interface is the first to swell and fracture, while the white sandstone has no obvious initiation of macroscopic cracks, showing good integrity.

(2) When the coal cracks expand to the coal-rock interface, the cracking path of large-scale cracks is blocked, and thus, coal cracks cannot penetrate the white sandstone. However, with the increase of the impact velocity, according to Griffith strength theory, when the stress at the crack tip is greater than the strength of the white sandstone, the white sandstone begins to crack and fail, and the main crack has a large angle with the loading direction, and the shear failure surface of the white sandstone increases with the increase of the impact velocity. The cracks begin to develop from the rock mass at the interface, which then penetrate the rock sample. It should be noted that at the impact velocities of 7.2 and $8.5 \mathrm{~m} / \mathrm{s}$, the white sandstone is damaged after multiple collisions with the bars, and cracks initiate in the sandstone edge.

(3) At low impact velocity, the white sandstone is split into large rock blocks by cracks. With an increase in the impact velocity, the degree of white sandstone fragmentation gradually increases, changing from large blocks to small ones. The coal sample also becomes more fragmented, and the size of the broken body transitions from granular to powdery.

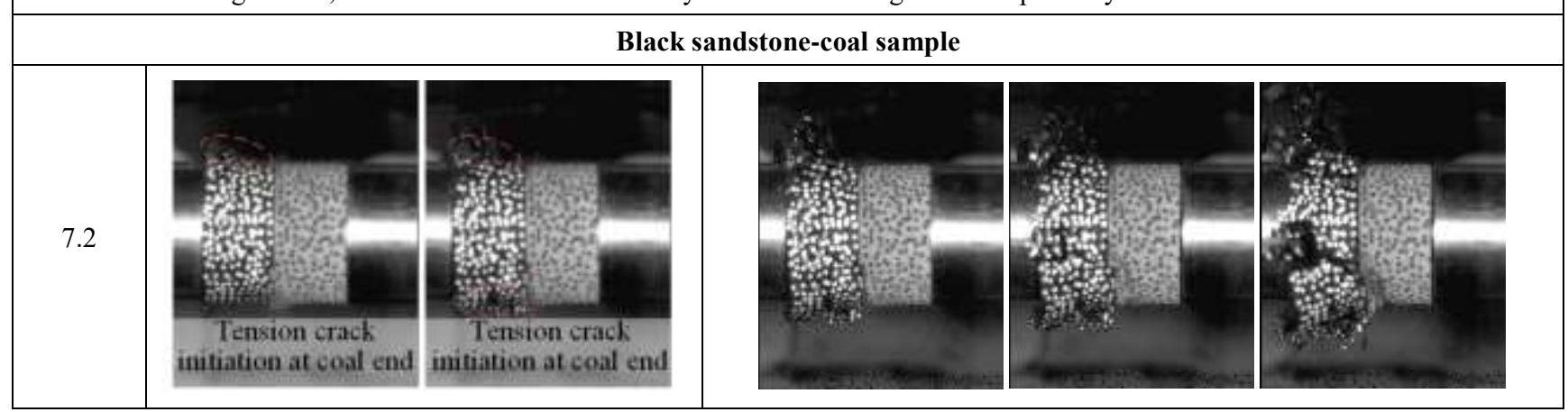




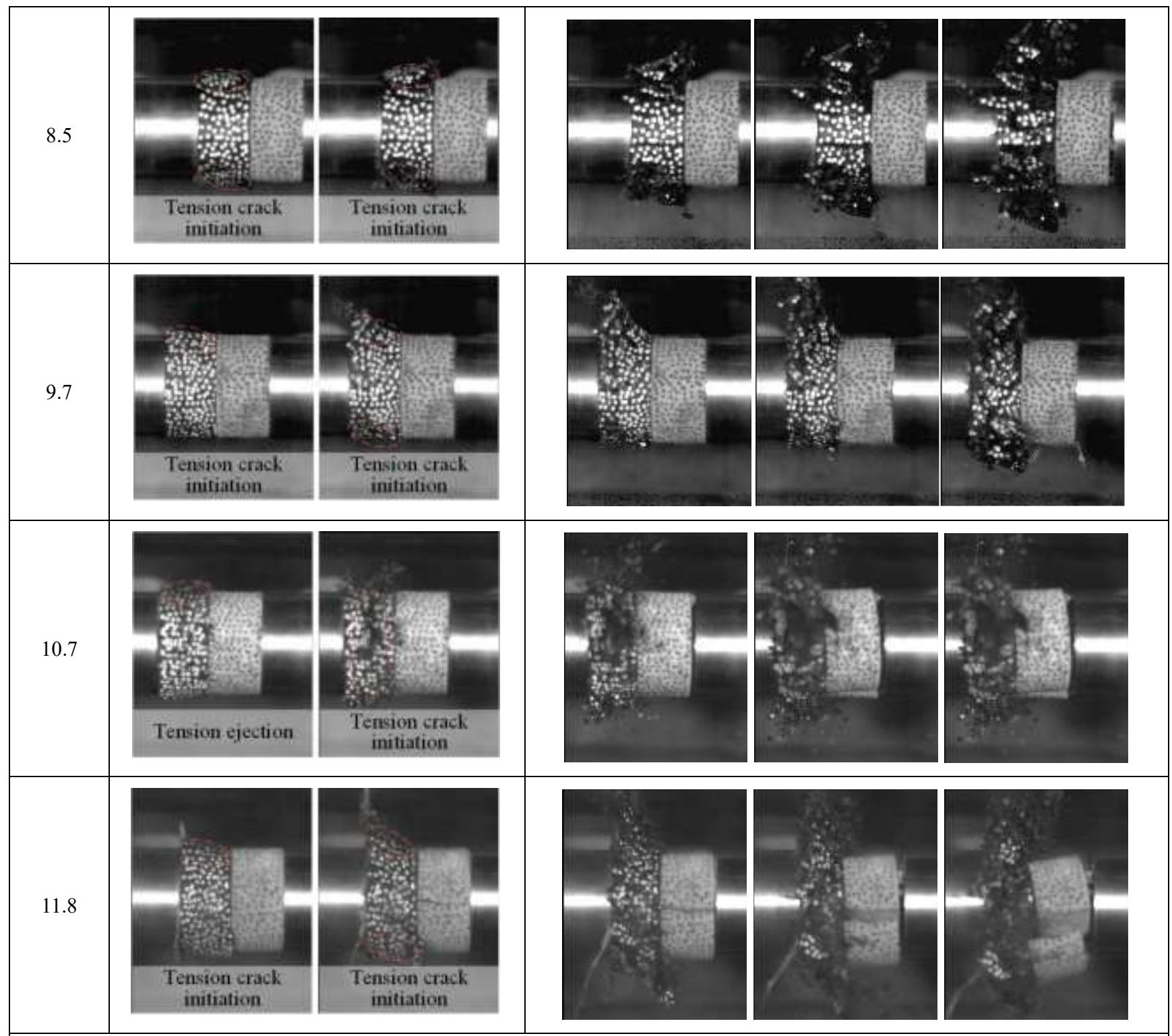

\section{Fracture pattern:}

(1) When the impact velocity is less than $9.7 \mathrm{~m} / \mathrm{s}$, the initiation of macroscopic cracks in the BS-C specimen is mainly concentrated in the coal, while the rock sample has no macroscopic cracks. When the impact air pressure is greater than $10.7 \mathrm{~m} / \mathrm{s}$, the black sandstone has a major crack propagation with a large angle to the loading direction, and the rock sample shows a single inclined plane shear failure.

(2) Under a low impact rate, the damage to the rock sample is small, and the integrity is good. However, small cracks inside the coal sample are fully developed, and the damage is relatively severe. The crack expansion and development are complicated, and the coal body is broken into granular-shaped particles. As the impact velocity increases, the sandstone begins to break and is divided into large pieces of rock by the cracks, and the coal sample fragments gradually turn powdery.

Note: The green line represents coal cracks, and the black line represents rock cracks.

From the characteristics of crack development in the $\mathrm{CRCB}$, it can be seen that the macro-cracking failure mostly occurs at the coal or rock end far away from the coal-rock interface with relatively low strength. When the cracks develop at the coal-rock interface, the crack expansion is blocked. However, as the impact velocity increases, when the stress at the tip of the crack is greater than the weakened strength of the coal or rock, the crack will continue to develop beyond the coal-rock interface. Under the same impact pressure, the initiation and development of cracks in the BS-C and WS-C specimens significantly differ from those of the M-C and SM-C 
specimens, which fail by bulging and splitting, i.e., the coal is split into blocks by cracks. In contrast, the BS-C and WS-C specimens have fully developed micro-cracks and the broken body of coal sample is granular and powdery. The absorbed energy of the CRCB specimen is mostly spent on the initiation and expansion of cracks ${ }^{30}$. However, it is difficult to analyse the difference in the degree of fragmentation and obtain the energy dissipation and dynamic characteristics of the $\mathrm{CRCB}$ specimen quantitatively under different lithologies only from the perspective of the development of cracks on the surface of the CRCB specimen. Therefore, it is necessary to analyse the crushing characteristics of the CRCB specimen.

\section{Analysis of crushing characteristics}

After impact crushing, the coal and rock masses were collected to obtain the damage patterns of the CRCB specimen under different impact pressures, as shown in Table 4. With an increase in the impact air pressure, the fragmentation degree of CRCB specimen gradually intensified, the volume of the broken body gradually decreased, and the grading characteristics were obvious.

Table 4. Failure modes of CRCB specimens

Impact
velocity $\mathrm{m} / \mathrm{s}$



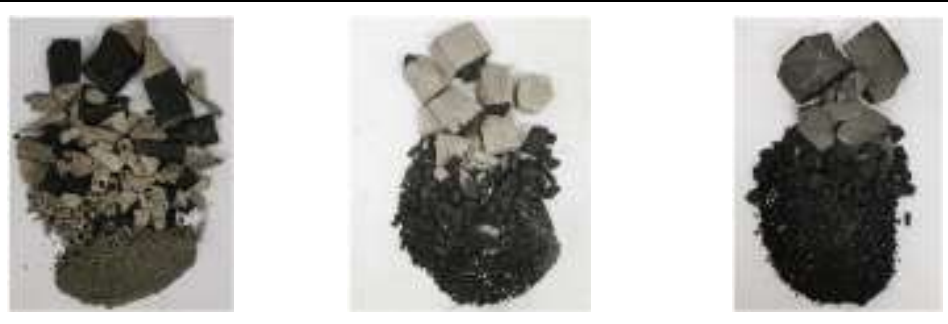

To further quantify and analyse the energy dissipation characteristics of each component of the CRCB, standard sieves with sizes of $25,20,16,10,5$, and $2.5 \mathrm{~mm}$ were selected, according to the characteristics of the fragments of the CRCB to screen and weigh the coal and rock fragments. In order to quantitatively compare the fragmentation size of CRCB specimen, the average particle size of fragmentation $\left(\mathrm{D}_{\mathrm{S}}\right)$ is used to represent the fragmentation degree of CRCB specimen.

$$
D_{s}=\frac{\sum \beta_{i} D_{i}}{\sum \beta_{i}}
$$

where $D_{i}$ is the mesh size, $\beta_{i}$ is the mass percentage of coal and rock fragments for the mesh size of $\mathrm{D}_{i}$.

The average particle size of fragmentation $\mathrm{D}_{\mathrm{S}}$ can be used to compare the degree of fragmentation of coal and rocks in a simple and intuitive way, but it can not directly reflect the distribution characteristics of the particle size of broken coal or rocks. In other words, if the broken CRCB specimen have the same $\mathrm{D}_{\mathrm{S}}$ does not mean that the mass of fragments on each screen is the same, so the distribution characteristics of fragmentation can not be truly quantified. The research results of many scholars show that the fragmentation of rock has fractal characteristics (D) 31,32. The fractal dimension of coal and rock specimens can reflect the distribution characteristics of coal and rock fragments intuitively and quantitatively.

$$
\begin{gathered}
D=3-\delta \\
\delta=\frac{\lg \left(M_{L_{e q}} / M\right)}{\lg L_{e q}}
\end{gathered}
$$

where $M_{\text {Leq }}$ is the mass of the fragments corresponding to the equivalent side length $L_{\text {eq }}, M$ is the mass of the fragments in the calculated size, and $D$ is the fractal dimension of the fragment. $\delta$ is the $M_{\text {Leq }} / M-L_{\text {eq }}$ slope value in double logarithmic coordinates, and $M_{\mathrm{Leq}} / M$ is the cumulative percentage content of fragments whose equivalent side length is less than $L_{\mathrm{eq}}$. 


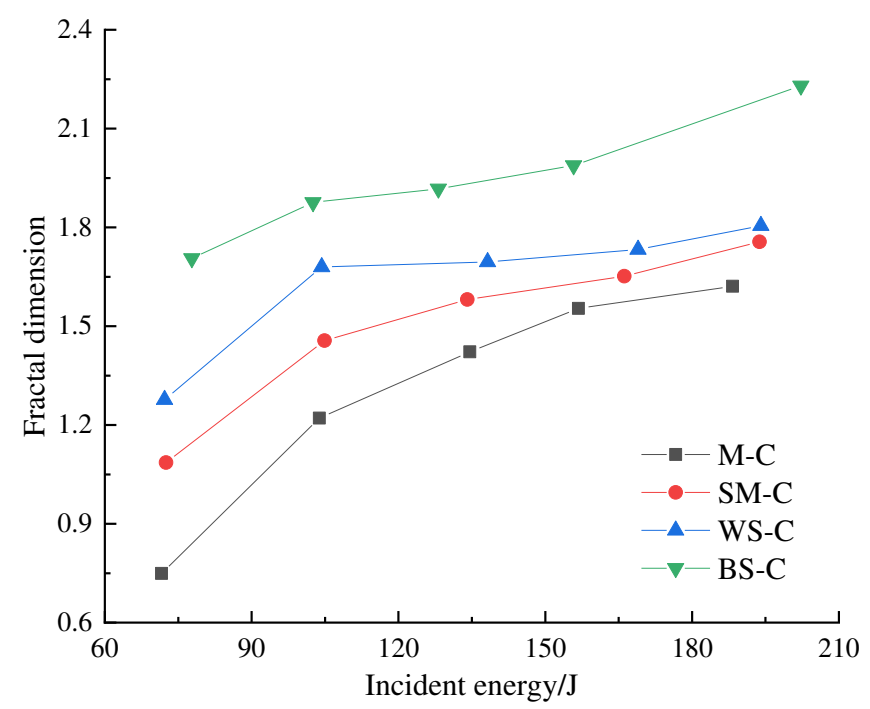

Fig. 11. Relationship between the fractal dimension and the incident energy of CRCB specimens

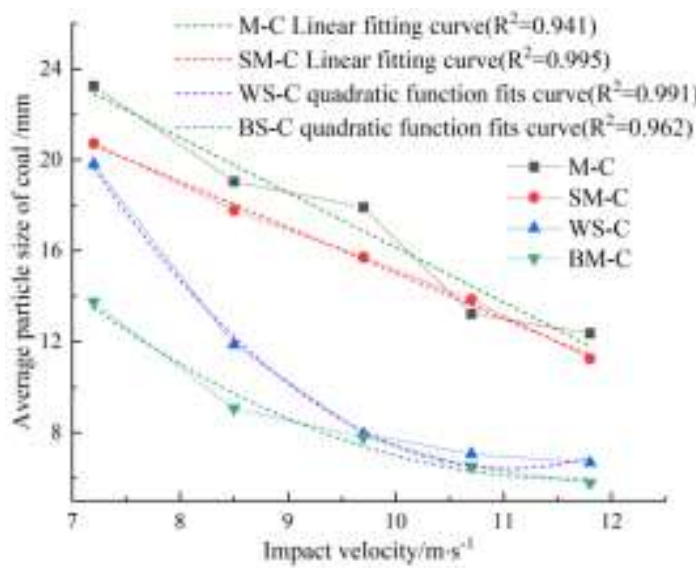

Fig. 12. Relationship between average particle size of coal and impact velocity

From the change in the fractal dimension of the CRCB specimen with the incident energy depicted in Fig.11, one can see that the fractal dimension of the four specimens increased with the incident energy. Nevertheless, the increment rate had a decreasing trend. It is worth noting that, theoretically, under the same incident energy, the lower the rock strength is, the higher the degree of fragmentation of the combined body, the more broken blocks there are, and the larger the fractal dimension. However, under the same incident energy, the fractal dimension of the BS-C specimens was the largest, followed by WS-C and SM-C, while that of M-C was the smallest. The rock component of the BS-C sample had good integrity and a low degree of fragmentation at an impact velocity of 10.7 $\mathrm{m} / \mathrm{s}$, according to its failure mode listed in Table 4 and screening results on its fragments in Fig.12, Fig.12 is drawn from the data in Table 5. The average coal particle size $D_{\mathrm{S}}$ was 6.52 , showing that the degree of fragmentation of coal significantly exceeded that of other CRCB specimens under the same impact velocity. The same situation was observed in CRCB specimens at other impact velocities. Under the same incident energy, as the strength of the rock increases, the rock plays a more important role in energy accumulation and transmission. The energy absorbed by the CRCB specimen is spent mainly to initiate and develop micro-cracks in the coal body, intensifying its fragmentation. When calculating the fractal dimension, the fractal of the coal body has a large contribution to the overall fractal of the combined body, resulting in a large overall fractal dimension of the CRCB specimen. 
Table 5. Screening test results of impact fragments of CRCB specimens

\begin{tabular}{|c|c|c|c|c|c|c|c|c|}
\hline \multirow{2}{*}{$\begin{array}{l}\text { Sample } \\
\text { number }\end{array}$} & \multirow{2}{*}{$\begin{array}{l}\text { Impact } \\
\text { velocity } \\
\left(\mathrm{m} \cdot \mathrm{s}^{-1}\right)\end{array}$} & \multicolumn{6}{|c|}{ Cumulative mass percentage of broken coal sample in each size interval } & \multirow{2}{*}{$\begin{array}{c}\text { Average particle } \\
\text { size } / \mathrm{mm}\end{array}$} \\
\hline & & $>25 \mathrm{~mm}$ & $20 \sim 25 \mathrm{~mm}$ & $16 \sim 20 \mathrm{~mm}$ & $10 \sim 16 \mathrm{~mm}$ & $5 \sim 10 \mathrm{~mm}$ & $2.5 \sim 5 \mathrm{~mm}$ & \\
\hline M-C-1 & 7.2 & 19.84 & 75 & 3.81 & 0 & 1.02 & 0.33 & 23.25 \\
\hline M-C-2 & 8.5 & 0 & 40.68 & 49.33 & 5.82 & 2.95 & 1.22 & 19.05 \\
\hline M-C-3 & 9.7 & 0 & 61.79 & 0 & 23.27 & 11.24 & 3.70 & 17.91 \\
\hline M-C-4 & 10.7 & 0 & 9.4 & 30.34 & 26.8 & 24.45 & 9.01 & 13.23 \\
\hline M-C-5 & 11.8 & 0 & 0 & 19.23 & 56.04 & 18.61 & 6.12 & 12.37 \\
\hline SM-C-1 & 7.2 & 23.82 & 43.82 & 10.42 & 12.96 & 6.53 & 2.45 & 20.73 \\
\hline SM-C-2 & 8.5 & 0 & 55.97 & 0 & 35.52 & 6.73 & 1.78 & 17.78 \\
\hline SM-C-3 & 9.7 & 0 & 38.13 & 9.7 & 30.83 & 15.66 & 5.68 & 15.72 \\
\hline SM-C-4 & 10.7 & 0 & 0 & 41.44 & 40.99 & 10.89 & 6.68 & 13.86 \\
\hline SM-C-5 & 11.8 & 0 & 0 & 21.07 & 38.93 & 23.82 & 16.18 & 11.25 \\
\hline WS-C- 1 & 7.2 & 20.52 & 39.92 & 8.74 & 22.5 & 5.82 & 2.5 & 19.81 \\
\hline WS-C-2 & 8.5 & 0 & 12.64 & 8.54 & 38.01 & 27.52 & 13.29 & 11.88 \\
\hline WS-C-3 & 9.7 & 0 & 0 & 0 & 26.38 & 46.60 & 27.02 & 7.94 \\
\hline WS-C-4 & 10.7 & 0 & 0 & 0 & 15.06 & 51.44 & 33.5 & 7.07 \\
\hline WS-C-5 & 11.8 & 0 & 0 & 0 & 12.43 & 47.46 & 40.11 & 6.68 \\
\hline BS-C-1 & 7.2 & 0 & 24.7 & 4.19 & 44.25 & 17.85 & 9.01 & 13.74 \\
\hline BS-C-2 & 8.5 & 0 & 0 & 0 & 41.24 & 39.88 & 18.88 & 9.06 \\
\hline BS-C-3 & 9.7 & 0 & 0 & 0 & 28.54 & 37.63 & 33.83 & 7.80 \\
\hline BS-C-4 & 10.7 & 0 & 0 & 0 & 12.80 & 40.27 & 48.93 & 6.52 \\
\hline BS-C-5 & 11.8 & 0 & 0 & 0 & 0 & 54.43 & 45.57 & 5.79 \\
\hline
\end{tabular}

Note: At the coal particle size below $2.5 \mathrm{~mm}$, the coal and rock particles are difficult to distinguish. Therefore, only broken coal and rock blocks with a particle size exceeding $2.5 \mathrm{~mm}$ were screened and weighed.

\section{Discussion}

(1) The physical and mechanical characteristics of rock affected the overall mechanical characteristics of the CRCB to a certain extent. When the physical and mechanical properties of the rock were in a certain range, the CRCB exhibited the characteristics of strain hardening, resulting in significantly improved overall strength.

(2) At a high impact rate, when the physical and mechanical parameters of the coal and rock are quite different, the rock may only experience the elastic stage after the coal has gone through the compression compaction-elastic stage-plastic failure stage. Due to the incompatibility of the deformation of coal and rock components, the stress-strain curves showed a state of multi-peak swinging. From the perspective of microscopic point, due to the great difference of mineral particle strength, arrangement order and cementation strength, the coal-rock composite experiences multiple rounds of different types of cementation bond breaking under the high impact rate, and the repetition of these complex processes leads to the state of multi-peak oscillation of the 
stress-strain curve. When the mechanical properties of coal and rock were relatively similar, such as in the SM-C specimen, the dynamic stress-strain curve was relatively smooth without the bimodal phenomenon, which was manifested as the change of the dynamic stress-strain slope.

(3) After the CRCB specimen failed, part of the broken body at the interface was still in the combined form (Table 3). This implies that the failure process of the CRCB was complicated. Therefore, the interface effects should be considered when analysing the deformation and failure of the combined structure instead of only from the coal or rock mass components.

(4) When calculating the overall fractal dimension of the CRCB, the author did not distinguish the coal and rock components. However, when calculating the average particle size of the coal sample broken block, the coal and rock components were separated and then sieved. Although this method may lead to a certain error from the real value, it was sufficient to reflect the energy dissipation pattern and the crushing characteristics of coal components.

\section{Conclusions}

The results obtained made it possible to draw the following conclusions:

(1) At low impact velocities, the difference in the wave impedance matching greatly impacted the stress wave propagation in the coal-rock combined body $(\mathrm{CRCB})$. However, as the impact velocity increased, the effect of wave impedance gradually weakened.

(2) Under impact loading, when the mechanical properties of coal and rock components differed greatly, the dynamic stress-strain curves of the CRCB mostly presented a "bimodal" distribution. With an increase in impact velocity, the peak strength and peak strain exhibited obvious strain rate effects, the incidence energy increases linearly while the proportion of reflected energy decreases linearly. The peak strength and ratio of the absorbed energy changed approximately as a power function. After reaching the peak stress, the combined body showed plastic deformation characteristics, with the stress-strain curve showing a decrease pattern of "ups and downs".

(3) The destruction of coal and rock masses is a progressive process. When the CRCB specimen was deformed and failed, crack initiation and failure mostly occurred in the coal or rock end far away from the coal-rock interface with relatively low strength. When the crack tip stress at the coal-rock interface was greater than the weakened strength of the coal or rock, the crack continue to develop across the coal-rock interface. With increasing of rock strength, the coal body is dominated by tensile failure, and the failure mode of rock samples gradually changes from tensile failure to shear failure.

(4)In terms of influencing the crushing degree of $\mathrm{CRCB}$, the influencing factors can be ranked in the decreasing order as follows: impact velocity $>$ rock strength $>$ wave impedance difference. The crushing degree of the coal body in the CRCB gradually intensified with the impact velocity and rock strength. The crushing particle size gradually changed from block to powder, and the fractal dimension gradually increased. When the strength of the rock was high, the rock was the impact energy accumulation body, which mainly played the role of energy accumulation and transmission, while the coal body was the impact energy release body. 


\section{Acknowledgments}

This work was supported by the National Key Research and Development Program of China(2016YFC0801402) and the Institute of Energy, Hefei Comprehensive National Science Center under Grant No.19KZS203.

\section{Author Contributions}

Wenjie Liu and Ke Yang wrote original draft paper, Litong Dou and Zhen Wei prepared all the figures, Xiaolou Chi and Rijie Xu did a lot of work in the revision. All authors have read and agreed to the published version of the manuscript.

\section{Competing interests}

The authors declare no competing interests.

\section{Additional information}

Correspondence and requests for materials should be addressed to Wenjie Liu

Reprints and permissions information is available at www.nature.com/reprints.

Publisher's note Springer Nature remains neutral with regard to jurisdictional claims in published maps and institutional affiliations.

\section{References}

[1]Petukhov, I. M.; Linkov, A. M. The theory of post-failure deformations and the problem of stability in rock mechanics. International Journal of Rock Mechanics and Mining Sciences 1979, 16(2), 57-76.

[2]Chen, S. J.; Yin, D. W.; Cao, F. W.; Liu, Y.; Ren K. Q. An overview of integrated surface subsidence-reducing technology in mining areas of China. Natural Hazards 2016, 81(2), 1129-1145.

[3]Chen, S. J.; Yin, D. W.; Jiang, N.; Wang, F.; Zhao, Z. H. Mechanical properties of oil shale-coal composite samples. International Journal of Rock Mechanics and Mining Sciences 2019, 123,104120.

[4]Dou, L. M.; Lu, C. P.; Mu, Z. L.; Gao, M. S. Prevention and forecasting of rock burst hazards in coal mines. International Journal of Mining Science and Technology 2009, 19(5), 585-591.

[5]Jiang, Y. D.; Wang, H. W.; Xue, S.; Zhao, Y. X.; Zhu, J.; Pang, X. F. Assessment and mitigation of coal bump risk during extraction of an island longwall panel. International Journal of Coal Geology 2012, 95, 20-33.

[6]Lu, C. P.; Dou, L. M.; Liu, B.; Xie, Y.S.; Liu, H. S. Microseismic low-frequency precursor effect of bursting failure of coal and rock. Journal of Applied Geophysics 2012, 79, 55-63.

[7]Lu, C. P.; Liu, G. J.; Liu, Y.; Zhang, N.; Xue, J. H.; Zhang, L. Microseismic multi-parameter characteristics of rock burst hazards induced by hard roof fall and high stress concentration. International Journal rock mechanics and mining science 2015, 76, 18-32.

[8]Huang, B. X.; Liu, J.W. The effect of loading rate on the behavior of samples composed of coal and rock. 
International Journal of Rock Mechanics and Mining Sciences 2013, 61, 23-30.

[9]Dou, L. M.; Lu, C. P.; Mu, Z. L.; Zhang, X. T.; Li, Z. H. Rock burst tendency of coal-rock combinations sample. Journal of Mining and Safety Engineering 2006, 23(01),43-46.

[10]Liu, J.; Wang, E. Y.; Song, D. Z.; Wang, S. H.; Niu, Y. Effect of rock strength on failure mode and mechanical behavior of composite samples. Arabian Journal of Geosciences 2015, 8(7), 4527-4539.

[11]Yang, K.; Liu, W. J.;; Dou, L. T.; Chi, X. L.; Wei Z. Fu Q. Experimental investigation into interface effect and progressive instability of coal-rock combined specimen. Journal of China Coal Society 2020, 45(05), 1691-1700.

[12]Gong S. Investigation of tensile and fracture mechanical properties of bituminous coal at different strain rates. Journal of Materials Research and Technology 2021, 15, 834-845.

[13]Gong, S.; Wang, Z.; Zhou, L.; Wang, W. Influence of Cyclic Impact Loading and Axial Stress on Dynamic Mechanical Properties of Burst-Prone Coal. Shock and Vibration 2021, 6649308.

[14]Ma, Q.; Tan, Y. L.; Liu, X. S.; Gu Q. H.; Li, X. B. Effect of coal thicknesses on energy evolution characteristics of roof rock-coal-floor rock sandwich composite structure and its damage constitutive model. Composites part B:Engineering 2020,198,108086.

[15]Yang, L.; Gao, F. Q.; Wang X. Q.; Li J. Z. Energy evolution law and failure mechanism of coal-rock combined specimen. Journal of China Coal Society 2019, 44(12), 3894-3902.

[16]Gong, S.; Zhou, L.; Wang, Z.; Wang, W. Effect of Bedding Structure on the Energy Dissipation Characteristics of Dynamic Tensile Fracture for Water-Saturated Coal. Geofluids 2021, 5592672.

[17]Zhao, Z. H.; Wang, W. M.; Yan, J. X. Strain localization and failure evolution analysis of soft rock-coal-soft rock combination model. Journal of Applied Sciences 2013, 13(7), 1094-1099.

[18]Zhao, T. B.; Guo, W. Y.; Lu, C. P.; Zhao, G. M. Failure characteristics of combined coal-rock with different interfacial angles. Geomechanics and Engineering 2016, 11(3), 345-359.

[19]Zhao, Z. H.; Lv, X. Z.; Wang, W. M.; Tan, Y. L. Damage evolution of bi-body model composed of weakly cemented soft rock and coal considering different interface effect. Springerplus 2016, 5(1), 292.

[20]Gong, F. Q.; Ye, H.; Luo, Y. The effect of high loading rate on the behaviour and mechanical properties of coal-rock combined body. Shock and Vibration 2018, 4374530.

[21]Li, C. J.; Xu, Y.; Chen, P. Y.; Li, H. L.; Lou, P. J. Dynamic Mechanical Properties and Fragment Fractal Characteristics of Fractured Coal-Rock-Like Combined Bodies in Split Hopkinson Pressure Bar Tests. Natural Resources Research 2020. https://doi.org/10.1007/s11053-020-09656-w.

[22]Han, Z. Y.; Li, D. Y.; Zhou, T.; Zhu, Q. Q.; Ranjith, P. G. Experimental study of stress wave propagation and energy characteristics across rock specimens containing cemented mortar joint with various thicknesses. International Journal of Rock Mechanics and Mining Sciences 2020, 131, 104352.

[23]Liu, X. S.; Tan, Y. L.; Ning, J. G.; Lu, Y. W.; Gu, Q. H. Mechanical properties and damage constitutive model of coal in coal rock combined body. International Journal of Rock Mechanics and Mining Sciences 2018, 110, 140-150. 
[24]Xie, B. J.; Zheng, Y. Dynamic mechanical constitutive model of combined coal-rock mass based on overlay model. Journal of China Coal Society 2019, 44(2), 463-472.

[25]Zhao, Z. H.; Wang, W. M.; Wang, L. H.; Dai, C. Q. Compression-shear strength criterion of coal rock combination model considering interface effect. Tunneling and Underground Space Technology 2015, 47, 193-199. [26]Yin, G. Z.; LI, X.; Lu J.; \& Song, Z. L. A failure criterion for layered composite rock under true triaxial stress conditions. Chinese Journal of Rock Mechanics and Engineering 2017, 36, (2), 261-269.

[27]Lu, J.; Huang, G.; Gao, H.; Li X.; Zhang, D. M. Mechanical Properties of Layered Composite Coal-Rock Subjected to True Triaxial Stress. Rock Mechanics Rock Engineering 2020, 53, 4117-4138.

[28]Yang, R. S.; Li, W. Y.; Fang S. Z.; Zhu Y.; Li, Y. L. Experimental study on impact dynamic characteristics of layered composite rocks. Chinese Journal of Rock Mechanics and Engineering 2019, 38(09), 1747-1757.

[29]SU, Z. G. Law and Control of Rockburst in Coal Pillar under the Condition of Special Thick and Hard Coal Seam in Hujiahe Coal Mine. China University of Mining and Technology 2015:3-4.

[30]Zhang, Z. X.; Kou, S. Q.; Jiang L. G.; Lindqvist P.-A. Effects of loading rate on rock fracture: fracture characteristics and energy partitioning. International Journal of Rock Mechanics and Mining Sciences 2000, 37(5), $745-762$.

[31]Xie, H. P.; Wang, J. N.; \& Qan, P. G. Fractal characters of micropore evolution in marbles. Physics Letters A 1996, 218(3-6), 275-280.

[32]Deng, Y.; Chen, M.; Jin, Y.; Zou, D. W. Theoretical analysis and experimental research on the energy dissipation of rock crushing based on fractal theory. Journal of Natural Gas Science and Engineering 2016, 33, 231-239. 